\title{
Judaísmo e identidad cristiana en el corpus de Cromacio de Aquileya
}

El presente trabajo procura determinar la motivación subyacente al discurso marcadamente antijudaico de Cromacio de Aquileya. Tras analizar las interpretaciones existentes sobre el fenómeno y reconsiderar críticamente los testimonios en que se han basado, se sugiere que -con independencia de cuál fuese la situación de la minoría judía en la propia Aquileya, circunstancia que ignoramos- la invectiva del obispo contra los Iudaei tuvo por intención proveer a los propios miembros de la comunidad cristiana de un contramodelo concreto en el que el individuo, acaso ignorante de las implicaciones de su elección, pudiese encontrar un buen ejemplo de lo que no era tolerado por la comunidad de la que formaba parte y de las consecuencias que aguardaban a quien no ciñese a ello sus conductas y creencias.

Palabras Clave: Cromacio de Aquileya; antijudaísmo; identidad cristiana; siglo IV.

Judaism and Christian Identity in the Corpus of Chromatius of Aquileia.- The aim of this paper is to determine the underling motivation for Chromatius of Aquileia's strongly anti-Judaic rhetoric. After analyzing the existing interpretations and critically reconsidering the testimonies in which they have been based, we suggest that -regardless of the situation of the Jewish minority in Aquileia-, the bishop's invective against Iudaei was motivated by the intention to provide to the members of the Christian community with a concrete counter model, an example of what was not to be tolerated by the Christian community and a demonstration of the consequences of such behavior, so that the Christian individual might guard against such errors in his own behavior and beliefs.

Keywords: Chromatius of Aquileia; Anti-Judaism; Christian Identity; $4^{\text {th }}$ Century.

\footnotetext{
"eln97@yahoo.com.ar
} 
Basta asomarse al Tractatus in Mathaeum y a los Sermones de Cromacio de Aquileya, obispo de la ciudad altoadriática entre los años 388 y $407 / 8$ de acuerdo a la cronología tradicional ${ }^{1}$, para percibir que los judíos y el judaísmo ocupan un lugar cuantitativamente destacado en su discurso. En efecto, evocado a través de expresiones colectivas-Iudaei, populus Iudaeorum, Israhel- o en alusión a alguna institución, jerarquía o facción judaica -synagoga, sacerdotes, scribae, doctores, pharisei-, el elemento judío se hace presente en 34 de las 62 piezas que conforman el Tractatus y en 21 de los 45 sermones cromacianos que han llegado hasta nosotros ${ }^{2}$. Tal como tendremos ocasión de corroborar por otra parte, la inmensa mayoría de las referencias a aquellos están teñidas de un fuerte matiz antijudaico ${ }^{3}$. El objetivo de este trabajo es analizar la razón de ser de tales circunstancias, tomando para ello en consideración tanto la propia obra cromaciana como todos los recursos heurísticos -materiales o literarios- que contribuyan al conocimiento de la situación del judaísmo en Aquileya y sus inmediaciones durante las décadas finales del siglo IV y las primeras del V. Antes de ello, convendrá repasar sucintamente algunas de las más influyentes teorías respecto del antijudaísmo cristiano durante la Antigüedad Tardía, así como también recordar el estado de la cuestión de los estudios cromacianos respecto de la problemática que aquí nos interesa.

${ }^{1} \mathrm{Ni}$ la fecha de la asunción del episcopado ni la de su muerte son seguras. Respecto de lo primero, la cautela aconseja afirmar que Cromacio ya había sido elevado al cargo episcopal en el año 392, cuando Jerónimo lo saludaba como episcoporum doctissime en el prólogo de su comentario al profeta Habacuc. Por lo que atañe a su deceso, lo más prudente parece afirmar que aún vivía en el año 406, cuando Juan Crisóstomo le dirige una epístola (núm. CLV) en agradecimiento por su intermediación en los conflictos mantenidos con la corte de Constantinopla, sin que sea posible determinar ni la fecha de su muerte ni si el aquileyense se encontraba aún en la metrópolis altoadriática cuando esta se produjo, cuestión insinuada por Scholz (Scholz, 1970, pág. 39) y en la que se encuentra trabajando actualmente Pier Franco Beatrice (Beatrice, 2011, pág. 57, nota 139).

${ }^{2}$ Estas cuantificaciones, aún siendo resultado de un prudente examen de los textos, no pretenden ser ni exactas ni definitivas, ya que sin duda pueden resultar apreciaciones distintas de las nuestras a partir de la interpretación que de cada término y de cada fragmento se efectúe. Tal es el caso de Françoise Thelamon, que indica que la polémica antijudía emerge en 23 de los Sermones cromacianos (Thelamon, 2001, pág. 99).

${ }^{3}$ Entendemos por «antijudaísmo» la aversión hacia el judío y el judaísmo cuyo fundamento es esencialmente religioso, en tanto que el «antisemitismo» involucra el desprecio por motivos raciales (al respecto, Ruether, 1974, pág. 116; Athans, 1991, pág. 120). 


\section{EL ANTIJUDAÍSMO CRISTIANO TARDOANTIGUO Y LA LITERATURA ADUERSUS IUDAEOS}

Dos son, a nuestro entender, los principales posicionamientos teóricos respecto del antijudaísmo cristiano durante la Antigüedad Tardía. Nos referimos a la teoría del conflicto, cuyo más célebre representante acaso sea Marcel Simon, y a aquella que, reconociendo en Rosemary Radford Ruether uno de sus hitos fundamentales, hace hincapié en el aspecto teológico de la cuestión. Repasamos, a continuación, lo esencial de cada una de ellas.

En su Verus Israel, Marcel Simon sostenía que «la raison profonde» del antijudaísmo expresado por la producción patrística durante el período comprendido entre los años 135 y 425 había sido «la vitalité religieuse du judaïsme». Esta vitalidad, señalaba, podía verificarse fundamentalmente en dos fenómenos: la continuidad del proselitismo judío y las múltiples formas constatables de lo que llamaba «contamination judéo-chrétienne» ${ }^{4}$, entre ellas las tendencias judaizantes intraeclesiásticas y, a nivel popular, la atracción que algunas prácticas religiosas judías ejercían sobre la población cristiana ${ }^{5}$. De tal modo, el antijudaísmo patrístico habría emergido «en définitive comme la réaction de défense de la hiérarchie orthodoxe contre le danger juif, le mal juif» ${ }^{6}$. Su razón de ser - «rendre les Juifs odieux» ${ }^{7}-$ se hallaba así, de acuerdo a Simon, en la realidad cotidiana, en el presente ${ }^{8}$.

Rosemary Radford Ruether propuso una explicación alternativa respecto del mismo fenómeno. En su Faith and Fratricide. The Theological Roots of Anti-Semitism, publicado en 1974, se apartó claramente de Simon al entender que el encendido discurso patrístico de cara al judaísmo no constituía una mera defensa contra el peligro judío sino una necesidad intrínseca de la autoafirmación cristiana ${ }^{9}$. Nacido en el seno mismo del

\footnotetext{
${ }^{4}$ Simon, 1964, págs. 273-274.

${ }^{5}$ Simon, 1964, págs. 356-357, 373-374.

${ }^{6}$ Simon, 1964, pág. 273.

${ }^{7}$ Simon, 1964, pág. 263.

${ }^{8}$ Simon, 1964, págs. 273-274.

${ }^{9}$ Ruether, 1974, pág. 181.
} 
judaísmo, señalaba pocos años más tarde, el cristianismo se había enfrentado en sus inicios a la necesidad de justificar tanto su escisión de la religión mosaica y, con ello, su propia existencia, como de legitimar la apropiación operada respecto de las Escrituras y de las esperanzas mesiánicas de Israel. La nueva fe se presentaba como la auténtica culminación de una religión que no había comprendido su propia tradición textual y, en consecuencia, no había reconocido en Jesús al Mesías prometido, mereciendo por ello la reprobación ${ }^{10}$. La demostración del error judío, entonces, se había constituido en un requisito indispensable para el cristianismo: Ruether afirmaba que no era posible predicar o enseñar cosa alguna sin justificar la novedad cristiana a partir del descrédito de Israel ${ }^{11}$. Miriam Taylor, quien compartió en lo fundamental los presupuestos teóricos de Ruether, ha sostenido que el antijudaísmo patrístico surgía como componente esencial de la formación de la identidad cultural de la Iglesia ${ }^{12}$ : el cristianismo no podía comunicar la verdad de su propia fe sin denunciar, al mismo tiempo, el error del pueblo judío. Había sido necesario, en consecuencia, construir y transmitir una imagen caricaturesca y despreciable del pueblo judío ${ }^{13}$ que ofreciera al cristianismo un reverso teológico sobre el cual afirmarse ${ }^{14}$.

${ }^{10}$ RUETHER, 1979, págs. 27-28.

${ }^{11}$ Ruether, 1979, pág. 29.

12 TAYlor, 1995, págs. 4-5, 142-143, 166.

${ }^{13}$ TAYLOR, 1995, pág. 128.

${ }^{14}$ TAYLOR, 1995, pág. 166. Guy G. Stroumsa, por su parte, ha criticado el carácter estático tanto de la teoría del conflicto simoniana como del antijudaísmo teológico de Ruether. A su entender, mientras su preocupación por el contexto social conducía a la primera a ignorar el poder autónomo de las creencias religiosas y su capacidad para formar la concepción del otro, la segunda concebía el discurso cristiano como si fuera una entidad claramente definida y rígida, ajena a las circunstancias históricas (STROUMSA, 1996, pág. 15). La unión entre los presupuestos esenciales de ambas posiciones teóricas condujo al autor a afirmar que la polémica, instrumento principal en la construcción de la afirmación de la identidad de un grupo (STROumsa, 1996, pág. 18), se había exacerbado a partir del siglo IV como consecuencia de las transformaciones ocurridas en las altas esferas de la política romana. La conversión del emperador al cristianismo, el progresivo retroceso del paganismo en el plano institucional y la continuada represión de las herejías habían hecho de la religión judía «the only remaining major negation of the universally proclaimed truth» (Stroumsa, 1996, pág. 20). En consecuencia, la tradicional esencia apologética, autojustificante, del discurso antijudaico había dejado lugar a la explícita 
Ya fuese que se pretendiese estimular el odio contra los judíos o que se buscase satisfacer las necesidades teológicas del cristianismo, es indudable que, desde cualquiera de estas perspectivas teóricas, existían buenas razones para que la intelectualidad cristiana persiguiese con sus escritos la denigración de la imagen del judío. Esta voluntad difamatoria se cristalizó en el surgimiento, consolidación y continuidad de una auténtica literatura aduersus Iudaeos, cuyos tópicos constituyentes, en atención de nuestro objetivo, conviene repasar brevemente ${ }^{15}$.

El elemento básico de la ignominia judaica residió en la incapacidad del pueblo de Israel para reconocer en Jesús al Mesías prometido. Desde la perspectiva cristiana, este hecho no solo justificaba la caracterización de los judíos como incrédulos, ignorantes, impíos, irracionales, pérfidos, ciegos, duros de corazón y de cerviz, sino que también contribuía a entender el acto que -como recordaba Ruether ${ }^{16}$ - no habría hecho más que colmar la capacidad de pecado de los judíos: el asesinato de Cristo. Proyectadas hacia el pasado y hacia sus propios tiempos por los escritores patrísticos, la incredulidad y la criminalidad devinieron rasgos esenciales y atemporales del pueblo judío: retrospectivamente, se apreciaban en su rechazo y asesinato de los profetas; en el presente, en el obstinado odio de los judíos hacia la Iglesia.

Desde un punto de vista estrictamente religioso, los Iudaei fueron presentados como idólatras y blasfemos. Ajenos al contenido profundo, simbólico, de una ley que les había sido dada no por su valor intrínseco sino como un freno a su depravación, se hallaban incapacitados para la vida espiritual. De allí su afición por el aspecto material de la existencia, que se plasmaba en su inclinación hacia todo tipo de vicios: eran seres carnales, adúlteros, amantes del dinero, del lujo, de los placeres de la mesa.

Por otra parte, su vilipendio se sustentaba en la amenaza que suponían tanto para el cristianismo como para la sociedad toda. En el primer as-

violencia verbal -más tarde legal y física- contra un colectivo que heredaba el lugar hasta entonces ocupado por el paganismo en tanto que representante de las fuerzas demoníacas y principal enemigo de la fe (Stroumsa, 1996, págs. 22-24).

${ }^{15}$ Para ello recurrimos a Simon, 1964, págs. 246-255; RuETHER, 1979, págs. 30-43; GonZÁLEZ SALINERo, 2000, cap. 4. Remitimos a esta bibliografía para el acceso a un completo repertorio de ejemplos concretos de los tópicos que a continuación presentamos.

${ }^{16}$ Ruether, 1979, pág. 30. 
pecto, frecuentemente asociado con el hereje, se hacía del elemento judío un enemigo y un perseguidor de la verdadera religión; en el segundo, se caracterizaba por su propensión a la revuelta, a la crueldad, a la malicia, a la iniquidad, rasgos estos que conducían incluso a prácticas infanticidas y al canibalismo.

Como ha señalado Raúl González Salinero, la denigración de los miembros del pueblo de Israel en la literatura patrística se extremaba al punto de hacer de ellos animales despreciables, asimilándolos a toros cebados, a terneros, a bestias ruidosas, a perros rabiosos, a serpientes venenosas, a zorros, a lobos, a escorpiones. Como tales, el judío expelía un olor nauseabundo ${ }^{17}$.

En el punto más alto del procedimiento difamatorio, la literatura aduersus Iudaeos insistía en la existencia de una relación particular, de un vínculo basado incluso en la filiación, entre el diablo y los judíos, siendo estos rehenes e instrumentos de aquel. Corolario lógico de semejante caracterización, un pueblo tal no podía más que haber sido apartado de las promesas salvíficas y, en consecuencia, sus integrantes se precipitaban inexorablemente hacia la condena eterna.

\section{IUDAEI EN EL CORPUS CROMACIANO: ESTADO DE LA CUESTIÓN}

Las apreciaciones en torno a la relación de Cromacio con los judíos y con el judaísmo emergen en buena parte de la producción académica vinculada a la figura y a la obra del aquileyense. En efecto, como veremos, diversos investigadores han vertido en sus respectivos trabajos reflexiones sobre la cuestión. Sin embargo, la inmensa mayoría de estas consideraciones se basaron en aquellas presentadas en 1969 y en 1977 respectivamente por Joseph Lemarié y Lellia Cracco Ruggini, autores que, en el momento de explicar la razón de ser del discurso antijudaico del obispo de Aquilea, incorporaron en sus análisis la noción simoniana de conflicto.

En su introducción a los Sermones, Joseph Lemarié sostuvo que, aún cuando la polémica antijudaica constituía un lugar común en las obras

${ }^{17}$ GonZÁlez Salinero, 2000, págs. 154-155. 
de muchos escritores patrísticos, en los textos cromacianos tal situación respondía «à une situation concrète bien précise», a saber, la presencia en Aquileya de una «minorité ferouchement opposée au christianisme ${ }^{18} »$. El fundamento de su apreciación respondía a una cuestionable presunción de índole racial y económica puesto que, según afirmaba, Cromacio debía de haber tenido «en face de lui une minorité puissante sur le plan des affaires», circunstancia inevitable, entendía, en el «monde commercial d'Aquilée ${ }^{19} \gg$. Apelaba, por otra parte, al epígrafe de Petrus, sobre el que volveremos luego, como prueba de la presencia judía en la región. Finalmente, incluía entre sus argumentos unas pocas líneas del Sermo XIII -sobre el que también regresaremos- referido al asesinato de los justos y de los profetas por los judíos ${ }^{20}$. Pese a su brevedad y a su escaso aparato argumentativo, las reflexiones de Lemarié constituyeron un punto de referencia para diversos investigadores ${ }^{21}$.

Las conclusiones a las que arribó Lellia Cracco Ruggini fueron, en lo sustancial, similares a las del religioso francés. En efecto, la investigadora advertía sobre la necesidad de comprender las invectivas antijudaicas cromacianas en atención de la «sotterranea coerenza che dovette loro conferire, necessariamente, il confronto con una precisa realtà locale, quella di Aquileia nell'ultimo ventennio del IV secolo d.C.» ${ }^{22}$. No obstante, el análisis de la investigadora italiana, a diferencia del de Lemarié, cimentaba sus propuestas en el examen de una amplia cantidad de recursos heurísticos, circunstancia que induda-

${ }^{18}$ LEMARIÉ, 1969, pág. 56.

${ }^{19}$ Lemarié, 1969, pág. 56. Este argumento había sido ya propuesto por Giovanni Brusin en 1949, cuando señalaba que «alla cosmopoli di Aquileia giungevano durante l'impero, senza posa, allettate dai traffici lucrosi, genti di ogni razza e favella, onde nessuna meraviglia che nella città avesse preso stanza anche una numerosa colonia semitica siriopalestinese» (BRUSIN, 1949, págs. 354-355).

${ }^{20}$ Lemarié, 1969 , pág. 56, nota 1.

${ }^{21}$ Así, por ejemplo, para Giulio Trettel y José Granados-Javier Nieva: el primero señaló que, durante el episcopado de Cromacio, en Aquileya «v'era una vivace ed aggresiva comunità ebraica» (TRETTEL, 1984, pág. 21). Los segundos, en tanto, repitieron sin más las palabras de Trettel al afirmar que «existía aún una comunidad hebrea vivaz y agresiva» (GRANADOS-NIEVA, 2002, pág. 14).

${ }^{22}$ Cracco Ruggini, 1977, pág. 353; similares nociones en Cracco RugGini, 2008, págs. 187-188. 
blemente contribuyó a la amplia aceptación de la que sus propuestas gozan aún en la actualidad ${ }^{23}$.

Su análisis partía de la convicción -refrendada por la propia autora poco tiempo atrás ${ }^{24}-$ de que, en las décadas finales del siglo IV, se había conformado una «potenziale "alleanza" anticattolica» ${ }^{25}$ integrada por herejes, judíos y paganos, aunados en el común rechazo de la divinidad de Cristo. Testimonio de ello encontraba en la epístola LXXV de Ambrosio de Milán ${ }^{26}:$ «¿qué otra cosa puede agradarles [a paganos y judíos] sino - que nunca suceda- que se niegue la divinidad de Cristo? Con ellos acuerda completamente bien el arriano, que dice que Cristo es una creatura, lo que también los gentiles y los judíos confiesan clarísimamente» ${ }^{27}$.

${ }^{23}$ Giuseppe Cuscito se adhirió explícitamente a los planteamientos de Cracco Ruggini (Cuscito, 1989, pág. 22; Cuscito, 1980, pág. 41; Cuscito, 1987, pág. 79). Carlo Truzzi (Truzzi, 1985, pág. 166, notas 265-266) y Rita Lizzi (Lızzı, 1989, págs. 162, 164-165 y nota 84 ) han seguido sus interpretaciones respecto de diversas cuestiones vinculadas con el judaísmo aquileyense. Aún cuando no incluye el trabajo de Cracco Ruggini en su bibliografía ni demuestra mayor interés por la cuestión judía, el mismo presupuesto teórico subyace a las reflexiones de Grazia Rapisarda en torno a la exégesis cromaciana. Ciertamente, la autora suponía que esta reconocía un fundamento marcadamente comunitario (RAPISARDA, 2006, pág. 33), emergiendo de la obra del aquileyense «un quadro della comunità ecclesiale di Aquileia nel IV secolo» (RAPISARDA, 2006, pág. 43). Especial mención merece Claire Sotinel que, en 2005, se apartó nítidamente de las apreciaciones de Cracco Ruggini al señalar que «à vrai dire, on ne sait rien des relations entre les deux groupes religieux; les passages des sermons de Chromace sur les Juifs relèvent des lieux communs de la polémique anti-juive [...]; le seul document direct en notre possession est celui du converti Petrus qui et Paparius inhumé dans la basilique de Grado au ve siècle» (Sotinel, 2005, págs. 174-175 y nota 13). Pese a ello, la investigadora francesa ha cambiado recientemente su parecer de modo radical, adhiriéndose explícitamente a las propuestas de Cracco Ruggini. Señala, en efecto, que «l'élément le mieux documenté par les sources est la présence d'une communauté juive consistante» (Sotinel, 2011, pág. 164), de la cual provee incluso una generosa descripción: «Il existe à Aquilée au v $\mathrm{v}^{\mathrm{e}}$ siècle (peut-être au $\mathrm{v}^{\mathrm{e}}$ siècle avancé) une communauté juive bien identifiée, dont certains membres sont des personnages aisés, profondément acculturés [...]. Les relations entre cette communauté et les chrétiens d'Aquilée ne semblent pas particulièrement tendues» (Sotinel, 2011, pág. 169).

${ }^{24}$ Cracco Ruggini, 2008, pág. 185.

${ }^{25}$ Cracco Ruggini, 1977, pág. 376.

${ }^{26}$ Cracco Ruggini, 1977, pág. 359.

${ }^{27}$ Ambr., Ep., LXXV, 13: Quid illis aliud potest placere nisi, quod absit, ut Christi divinitas denegetur? Cum his plane bene convenit Arriano qui creaturam Christum dicit, quod etiam gentiles ac Iudaei promptissime confitentur. 
Esta alianza, señalaba, se había manifestado en la propia Aquileya en ocasión del concilio antiarriano reunido en la metrópolis altoadriática en el año 381. Cracco Ruggini recordaba que, en aquella ocasión, Paladio, obispo de Ratiaria acusado de heterodoxia, había exigido como condición para prestarse al interrogatorio que participasen de las cesiones auditores y exceptores externos. Invitado por Ambrosio de Milán a especificar qué auditores se deseaban, Paladio respondió sunt hic honorati multi ${ }^{28}$. La investigadora creía dilucidar la identidad de dichos honorati a partir de la lectura de un pasaje de la apología paladiana llegada hasta nosotros: entendía que, en Aquileya, Paladio «chiedeva infatti che la sua ortodossia fosse vagliata, Scritture alla mano, anche da dotti pagani [...] nonché da esperti giudaici dell'esegesi veterotestamentaria», infiriendo de tal circunstancia que debía de haber cultores de la religión judía entre los «exmagistrati municipali» de la ciudad ${ }^{29}$.

La materialización de esta alianza en Aquileya resultaba fundamental en el esquema interpretativo de la autora, puesto que a su luz debía entenderse el discurso cromaciano de cara a la minoría judía ${ }^{30}$. Desde el primer momento significativo de su carrera eclesiástica, esto es, desde su activa participación en el concilio del 381, el futuro obispo se había percatado -sostenía la autora- de que la minoría herética podía hallar un eventual sostén a sus propias interpretaciones de la Escritura «anche fra i membri della locale comunità giudaica, a quanto pare cospicui, in qualche caso, per censo e per rango sociale» ${ }^{31}$.

La aceptación de la existencia de dichos honorati judíos exigía la presencia en la metrópolis altoadriática de una comunidad mosaica. La autora presentaba entonces diversos testimonios, arqueológicos y literarios,

\footnotetext{
${ }^{28}$ Cracco Ruggini, 1977, p. 360 . El texto del concilio al que la autora alude es Act. conc. Aquil, 669-677: Ambrosius episcopus dixit: «Acquiescis ut cetera legantur Arri, Palladi?» Palladius dixit: «Date auditores, veniant et ex utraque parte exceptores; non potestis esse iudices si auditores non habuerimus neque ex utraque parte venerint qui audiant, non vobis respondemus». Ambrosius episcopus dixit: «Quos quaeritis auditores?» Palladius dixit: «Sunt hic honorati multi».

${ }^{29}$ Cracco Ruggini, 1977, pág. 360. Claire Sotinel asume la validez del razonamiento de Cracco Ruggini (Sotinel, 2011, pág. 164).

${ }^{30}$ Cracco Ruggini, 1977, pág. 362.

${ }^{31}$ Cracco Ruggini, 1977, pág. 363.
} 
tendientes a demostrar que, efectivamente, habitaba allí un importante colectivo judaico. Acudía, en primer lugar, al ya aludido y cuestionable argumento referente al rol comercial y cultural de la ciudad ${ }^{32}$. De tal circunstancia daban cuenta también, a su entender, los epígrafes de Lucius

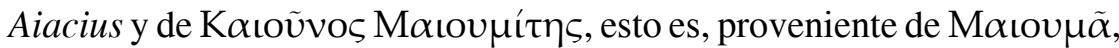
centro palestino y puerto de Gaza ${ }^{33}$. En tanto, dos documentos, sobre los que volveremos enseguida, probarían la existencia de una sinagoga en la ciudad. Por un lado, la inscripción de Ursacia hallada en la catacumba judía de Vigna Randanini, Roma; por otro, la epístola LXXIV de Ambrosio de Milán ${ }^{34}$.

¿Cuál había sido la actitud del obispo ante esta comunidad, notable «per qualità prima ancora che per quantità», que incluía «numerosi personaggi agiati, in grado di ofrirsi un edificio cultuale spazioso ed elegante [...]; personaggi in qualche caso talmente radicati nella vita cittadina da esserne stati addirittura protagonisti, come magistrati locali» ${ }^{35}$ ? Cromacio habría adoptado un «atteggiamento pratico deciso e coerente: rigida separazione affiancata da programmatica non belligeranza, che intendeva rifiutare agli ebrei qualsiasi pretesto di vittimismo ${ }^{36}$ mediante el recurso a los lugares comunes del antijudaísmo patrístico ${ }^{37}$. El proceder cromaciano dejaría percibir, además, «la paura pratica, concreta, di possibili in-

${ }^{32}$ Cracco Ruggini, 1977, pág. 363. En igual sentido se expresa Claire Sotinel: «L'existence prolongée d'une importante et vivante communauté juive convient au caractère commercial et cosmopolite d'Aquilée [...] Peut-on imaginer un port méditerranéen en relations commerciales régulières avec l'Orient dans lequel il n'existerait pas de communauté juive?» (Sotinel, 2011, pág. 169).

${ }^{33}$ Cracco Ruggini, 1977, pág. 367-368, 371, notas 36 y 42. No dedicaremos a la

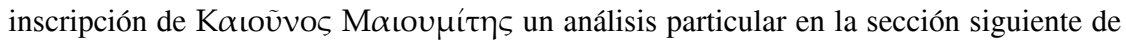
este trabajo puesto que se trata apenas de uno de los muchos epígrafes aquileyenses que contienen un antropónimo semita o un locativo vinculado con Palestina, sin que esto signifique que los sujetos en ellos evocados hayan sido efectivamente judíos (para el caso de esta inscripción, véase Noy, 1993, pág. XIII). Aún inédito en 1977, el epígrafe, cuyo contexto de recuperación se desconoce, fue publicado en BRusin, 1991-1993, núm. 3107 y, con amplio comentario, en VergONe, 2007, núm. 124.

${ }^{34}$ Cracco Ruggini, 1977, pág. 363.

${ }^{35}$ Cracco Ruggini, 1977, pág. 372.

${ }^{36}$ Cracco Ruggini, 1977, pág. 373.

${ }^{37}$ Cracco Ruggini, 1977, pág. 374. 
fluenze ebraiche sul costume cristiano, attraverso contatti e consuetudini quotidiane» ${ }^{38}$. En consecuencia, su prédica tendía a «la separazione più rigorosa e il rigido isolamento», concebidos como «l'unica arma da usarsi nei loro confronti» ${ }^{39}$. De tal modo, a diferencia de lo expresado dos décadas atrás ${ }^{40}$, la investigadora italiana se aproximaba en esta ocasión a los presupuestos esenciales de la teoría del conflicto formulada por Simon: la razón de ser del discurso antijudaico del obispo de Aquileya radicaba en la amenaza representada por la potencial contaminación que un judaísmo todavía vital suponía para la comunidad cristiana.

Solo en este momento la obra cromaciana era tomada en consideración por Cracco Ruggini, y no para inferir a partir de los Sermones y del Tractatus in Mathaeum la situación del judaísmo aquileyense sino para corroborar en ellos las apreciaciones vertidas. Siendo así, el Sermo XXVIII, en el que Cromacio se refería a la vida presente como una competencia entre católicos, judíos, filósofos y herejes por el premio de la inmortalidad, constituía a decir de la autora -y de igual modo para aquellos que han seguido sus propuestas- un testimonio del «articolarsi della polemica cromaziana nello schema tripartito di una lotta contro giudei, eretici e pagani» ${ }^{41}$. El Sermo XVI, en que el obispo de Aquileya aludía a judíos y gentiles que sollemnitatem huius uigiliae nostrae tamquam propriam

${ }^{38}$ Cracco Ruggini, 1977, pág. 379.

${ }^{39}$ Cracco Ruggini, 1977, pág. 379. En el mismo sentido se expresa Cracco Ruggini en su artículo del 2008: «pertanto, onde evitare "contagi" pericolosi, Cromacio ebbe a predicare con insistenza una rigorosa separazione tra i fedeli cristiani e gli ebrei con cui costoro vivevano gomito a gomito, isolando questi ultimi [...] Si trattava di una strategia pratica ben più efficace dell'astratta polemica teologica» (CRACCO RUGGINI, 2008, págs. 187-188).

${ }^{40}$ En aquella ocasión Cracco Ruggini señalaba que «in tutte le Diocesi più importanti della regione, vescovi come Cromazio di Aquileia, Zeno de Verona, Gaudenzio di Brescia, lo stesso Ambrogio di Milano e, in misura un po' minore, Massimo di Torino, si mostrano assai tolleranti nei confronti degli ebrei locali, disapprovandoli più che altro nel campo dogmatico e non superando mai i limiti di un anti-giudaismo strettamente letterario: il che concorrerebe a escludere l'esistenza di colonie semitiche veramente importanti e "pericolose" da un punto di vista sia religioso che commerciale (come invece lo stesso Simon, lo Jalabert ed altri sembrano portati a credere)» (CRACCO RUGGINI, 1959, págs. 210-211).

${ }^{41}$ Cracco Ruggini, 1977, pág. 376; Cuscito, 1980, págs. 46-47; Cuscito, 1987, pág. 84. 
celebrant ${ }^{42}$, daría cuenta del «avanzatissimo processo di "acculturazione" e compenetrazione di questi gruppi etnico-religiosi minoritari nel connettivo sociale e culturale cittadino» ${ }^{43}$. Entendía, evidentemente, que había en la ciudad judíos y paganos que celebraban la Pascua cristiana ${ }^{44}$.

Únicamente Françoise Thelamon ha evitado el establecimiento de un vínculo causal entre conflicto interreligioso y discurso antijudaico cromaciano. La investigadora encontraba en el Sermo XVI el único documento relativo a los vínculos existentes entre ambos colectivos en Aquileya durante la Antigüedad. Y ni este ni ningún otro testimonio daba cuenta, a su entender, de una relación dificultosa ${ }^{45}$. Consistiendo básicamente en la denuncia de la negativa judía a reconocer la divinidad de Cristo y en la imputación de falta de fe, la invectiva de Cromacio contra Israel dejaba percibir una esencia fundamentalmente religiosa, incluso teológica, y se manifestaba de manera «globalement modérée» ${ }^{46}$. En efecto, no era posible percibir en la predicación antijudaica del aquileyense, a decir de

${ }^{42}$ Véase la nota 72, infra.

${ }^{43}$ Cracco Ruggini, 1977, págs. 380-381; Cracco Ruggini, 2008, pág. 187. Sin hacer referencia alguna a la localización de los Iudaei y de los gentiles que celebrarían la Pascua, Cuscito alude al fragmento en cuestión señalando que «Cromazio debe constatare l'universale gaudio della celebrazione pasquale, cui non possono sottrarsi neppure giudei e pagani nonostante la loro estraneità al mistero della risurrezione» (Cuscito, 1987, pág. 86).

44 «Di particolare interesse appare, in questo contesto, il cenno dell'omelia XVI agli iudaei di Aquileia che, non diversamente da certi pagani, erano portati in qualche modo a festeggiare tamquam propriam la sollemnitas cristiana della veglia pasquale» (CRACCO RugGini, 1977, pág. 380). En el mismo sentido se expresa Carlo Truzzi al indicar que «siamo informati dal nostro vescovo che alcuni ebrei locali guardano con intima simpatia alla festa dei cristiani per la pasqua» (TRUZzI, 1985, pág. 166). Sotinel, por su parte, asume la celebración de la vigilia pascual por parte de los gentiles y de los judíos de Aquileya, pero entiende que se trataría de una participación profana, limitada al ámbito familiar o vecinal (Sotinel, 2011, págs. 172-174).

45 Thelamon, 2001, págs. 112-113. Tres veces insiste la autora sobre la falta de evidencias de conflicto. La primera en la página 110, cuando afirma que Cromacio «ne semble polémiquer vraiment avec les Juifs de son temps ni avoir soutenu de réelles controverses avec les docteurs de la communauté juive locale»; la segunda en la página 112, al decir que «on ne perçoit pas à travers les sermons de Chromace de contentieux particulier avec la communauté juive local»; la tercera, en la pág. 114: «il ne semble pas y avoir eu à Aquilée de conflit d'influence, de rivalités prosélytes ni de controverses savantes entre Juifs et chrétiens».

46 Thelamon, 2001, pág. 114. 
Thelamon, «ni les accusations de débauche et d'immoralité ni le recours aux procédés de l'invective et de la polémique utilisés par d'autres» ${ }^{47}$, apreciación que cuestionaremos más adelante. Así pues, el énfasis cromaciano en la perfidia de los judíos del pasado y del presente, esto es, en su falta de fe voluntaria y obstinada ${ }^{48}$, rechazo de la vida ofrecida por Cristo y elección de la muerte, habría tenido por finalidad establecer una oposición completamente retórica entre judíos y cristianos: la mala elección de los primeros servía para «exalter le bon choix» de estos últimos ${ }^{49}$. Cromacio retomaba, de tal modo, un tópico de la literatura antijudaica para instruir y fortalecer en la fe a sus fieles, especialmente a los catecúmenos y neófitos, a partir de la confrontación con el contramodelo judío ${ }^{50}$.

Las reflexiones de Thelamon, sin embargo, no han hallado hasta aquí repercusión. En efecto, predomina aún en el marco de los estudios cromacianos la certeza de que la razón de ser del discurso antijudaico del obispo aquileyense debe buscarse en la amenaza que el colectivo mosaico presente en la metrópolis altoadriática suponía para la comunidad cristiana local $^{51}$. Siendo así, es inicialmente necesario examinar crítica y detenidamente los recursos heurísticos, tanto materiales como literarios, en que tal hipótesis se ha sustentado.

\section{RECONSIDERACIÓN DE LOS RECURSOS HEURÍSTICOS EN TORNO AL JUDAÍSMO AQUILEYENSE}

La documentación material contribuye escasamente al conocimiento del judaísmo aquileyense durante la Antigüedad ${ }^{52}$. Aún cuando desconfiemos, como dijimos, del razonamiento de acuerdo al cual habría existido en Aquileya una importante comunidad judía puesto que era un enclave

\footnotetext{
${ }^{47}$ Thelamon, 2001, pág. 114, nota 87.

${ }^{48}$ Thelamon, 2001, pág. 102.

49 Thelamon, 2001, pág. 110.

${ }^{50}$ Thelamon, 2001, pág. 113.

${ }^{51}$ Véase la nota 23, supra.

${ }^{52}$ Para una más amplia consideración de los testimonios materiales que a continuación abordamos, además de la bibliografía consignada en las notas 53-58 de este trabajo, véase Noce, en prensa (a).
} 
comercial de primera importancia, la presencia de tal comunidad en la ciudad y sus inmediaciones parece segura a partir de dos epígrafes. El primero, procedente de la catacumba judía de Vigna Randanini, Roma, datable entre los siglos III y IV, recuerda a Ursacia, «hija de Ursacio de Aquileya, gerusiarca» ${ }^{53}$. El segundo, en tanto, ha sido localizado entre los restos de una pequeña iglesia paleocristiana situada bajo la basílica de Sant'Eufemia, en Grado, a una decena de kilómetros de Aquileya. La inscripción conmemora a Pedro, judío converso al cristianismo en algún momento del siglo $\mathrm{v}^{54}$. Pese a ello, nada más puede decirse sobre el judaís-

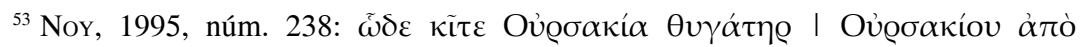

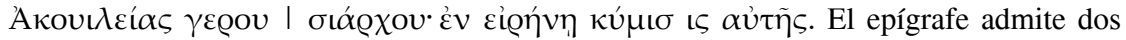
interpretaciones. La primera de ellas, de acuerdo a la cual Ursacio, procedente de Aquileya, desempeñó su función sinagogal en Roma, conduce a la siguiente traducción: «aquí yace Ursacia, hija de Ursacio de Aquileya, gerusiarca. Que su descanso sea en paz» (CALDERINI, 1930, pág. 401; FREY, 1936, núm. 147; Cuscito, 1972, pág. 245, nota 61; MAZzolenI, 1987, pág. 313; Noy, 1995, núm. 238; GiovanNini, 2008, pág. 172). La segunda lectura, en tanto, entiende que el cargo habría sido desempeñado en Aquileya donde, en consecuencia, debía entonces funcionar una casa de culto judía. En tal caso, la traducción pertinente sería «aquí yace Ursacia, hija de Ursacio, gerusiarca de Aquileya. Que su descanso sea en paz» (Brusin, 1949, pág. 355; Brusin, 1949a, c. 29; LuZZATo, 1950, págs. 143-144; Brusin, 1953-1954, c. 62; Cracco Ruggini, 1959, pág. 216 y nota 75; Zovatto, 19601961, pág. 57; Vattioni, 1972, c. 125; Cracco Ruggini, 1977, pág. 363; Thelamon, 2001, pág. 98, nota 8). Zevì Avneri (Avneri, 1962, pág. 466 y nota 2) y Claire Sotinel (Sotinel, 2011, p. 165), aún sin decantarse por una u otra lectura, han sostenido que la inscripción asegura la presencia de una comunidad judía importante en Aquileya. Aceptamos la primera interpretación atendiendo a las observaciones lingüísticas y epigráficas efectuadas por Danilo Mazzoleni, quien, por un lado, sostuvo que si se hubiese deseado indicar el desempeño de la función sinagogal en Aquileya no se habría utilizado la preposición àđò sino el locativo; por otro, recordó el hecho de que las inscripciones romanas no se refieren a cargos ejercidos en otras comunidades (MAZzolens, 1987, pág. 313).

${ }^{54}$ Brusin, 1991-1993, núm. 3330: Hic requiescit | Petrus qui Papa | rio fil(ius) Olimpii Iu $\mid$ daei solusque $\mid$ ex gente sua $\mid$ ad XPI (= Christi) meruit $\mid$ gratiam perveni $\mid$ re et in hanc s(an)c(t)am | aulam digne sepul | tus est sub d(ie) pr(i)d(ie) | id(us) Iul(ias) ind(ictione) quarta. Respecto de su localización temporal, las opiniones han variado: en 1947, Giovanni Brusin se inclinaba por situarlo, en base a criterios estilísticos, hacia finales del siglo V o comienzos del VI (BRusin, 1947, págs. 19-20). Paolo Lino Zovatto, por su parte, pensaba en el año cuarto de alguna de las indicciones de la primera mitad del siglo v, es decir, 406, 421, 436 o 451 (BRusin- ZovatTo, 1957, pág. 458 y nota 72), datación que siguen Carlo Truzzi (Truzzi, 1985, pág. 166, nota 262), David Noy (Noy, 1993, núm. 8) y a la que parece adherir también Brusin en sus Inscriptiones Aquileiae (BRusin, 1991-1993, núm. 3330). Giuseppe Cuscito se ha inclinado por algún momento en torno a la mitad del siglo v (Cuscito, 1972, págs. 245-247), mientras que Lellia Cracco Ruggini, en atención 
mo en la metrópolis altoadriática a partir de los recursos arqueológicos y epigráficos que han llegado hasta nosotros: si bien el debate en torno al carácter sinagogal o eclesiástico de la primera fase del edificio de culto situado en la localidad de Monastero se reabre esporádicamente, los argumentos presentados en el curso de las discusiones parecen suficientes para refrendar la segunda alternativa ${ }^{55}$; el epígrafe de Lucius Aiacius, Iudaeus ${ }^{56}$, resulta poco provechoso, puesto que, por un lado, data del siglo I a. C.; por otro, siendo aquel un liberto, bien podría tratarse de un expatriado y, consecuentemente, su presencia en la ciudad no testimoniaría siquiera la existencia de una comunidad judía en ella ${ }^{57}$; desconociéndose por completo el contexto de su recuperación, las tres luminarias decoradas con la menorá que se conservan en el Museo Archeologico Nazionale de Aquileya, cuya datación remite al siglo IV, carecen de valor documental ${ }^{58}$.

de distintos elementos paleográficos, históricos y arqueológicos, propuso los años 465 o 480 (Cracco Ruggini, 1980, págs. 140-147). Apelando a cierta similitud textual entre el epígrafe y el Sermo X, 68-70 del obispo aquileyense, Rita Lizzi sugirió, a nuestro entender sin suficiente sustento, que «si potrebbe tentare di datare l'iscrizione al tempo di Cromazio» (LizzI, 1989, págs. 158-159 y notas 70-71).

${ }^{55}$ Siendo imposible reproducir aquí el debate, remitimos a los principales hitos de la discusión. A favor de la tesis sinagogal: Brusin, 1949: passim; Brusin, 1949a, passim; Cracco Ruggini, 1959, págs. 195-202; Zovatto, 1960-1961, págs. 53-59; Polacco, 1973, págs. 125-126, 136-137, 144-146; CRACCo RUGGinI, 1977, págs. 366-371; LizZi, 1989, pág. 162, nota 84. Aunque no de modo explícito, parece defender la hipótesis VATTIONI, 1972, cc. 126-128. Por el contrario, suponen la naturaleza eclesiástica del implante originario Brusin-Zovatto, 1957, pág. 308, nota 333 y pág. 344; Forlati Tamaro, 1965, págs. 662670; Bertacchi, 1965, cc. 80 y 111-117; Noy, 1993, pág. XIV; Thelamon, 2001, pág. 98. Más recientemente, Giulia Francesca Grassi ha retomado la cuestión, concluyendo que «in sostanza, l'analisi degli antroponimi attestati all'interno della basilica evidenzia come essi possano difficilmente essere considerati indicatori di un uso dell'edificio come sinagoga» (GRASSI, 2009, c. 426).

${ }^{56}$ Brusin, 1991-1993, núm. 75: L. Aiacius |P. l. Dama |Iudaeus por | tor v(ivus) $s($ ibi) f(ecit). La inscripción no ha suscitado mayores debates. Tratan sobre ella CALDERINI, 1930, pág. 245; Frey, 1936, núm. 643; Brusin, 1949, pág. 355; Luzzato, 1950, pág. 143; Brusin, 1953-1954, c. 62; Cracco Ruggini, 1959, pág. 216, nota 75; Avneri, 1962, pág. 466, nota 2; Cuscito, 1972, pág. 245; Cracco Ruggini, 1977, págs. 367-368, nota 36; Noy, 2003, núm. 7; Giovannini, 2008, pág. 172.

${ }^{57}$ Françoise Thelamon, por el contrario, sostiene que la inscripción es un buen testimonio de la presencia judía en la ciudad (Thelamon, 2001, pág. 98, nota 7).

${ }^{58}$ Sobre las luminarias, véase Frey, 1936, núm. 643; Avneri, 1962, passim; GiovanNinI, 2008, págs. 172-173. 
Del mismo modo, escaso provecho reporta la documentación literaria, cromaciana y no cromaciana, generalmente evocada para el análisis de la situación del judaísmo aquileyense durante la Antigüedad. Reconsideremos, en las páginas siguientes, tales testimonios.

\subsection{El fragmento paladiano}

Hemos señalado que el desarrollo argumentativo de Cracco Ruggini depende, en buena medida, de la lectura que efectúa del fragmento paladiano de los Scholia in concilium Aquileiense. Vale la pena exponer aquí el pasaje al que la autora se refiere a fin de advertir que las palabras del obispo depuesto en el concilio de Aquileya no guardaban ninguna relación con el orden político, social y/o religioso imperante en la ciudad. En la conclusión de su apología, tras elogiar a la ciudad de Roma por haber asistido a la pasión de los apóstoles, poseer sus reliquias y albergar a hombres ejemplares por su sabiduría y nobleza, Paladio desafiaba a sus acusadores:

Si tenéis alguna confianza en vuestra fe, profesemos la fe ante el senado de esta misma ciudad durante treinta o cuarenta días seguidos de acuerdo a la autoridad de todas las Escrituras con tratados redactados a tal fin. Nuestros discursos serán presentados a los auditores tanto para que sean dados a conocer en la ciudad por la recitación pública como para que sean enviados, en el informe de los auditores, a todas las iglesias del mundo por orden del emperador. Sepan que, si se decide esto, en la audiencia deberán ser admitidos entre los cristianos también seguidores del culto gentil [gentilitatis cultores], y estudiosos de la antigua ley [ueteris legis studiosi], puesto que, en lo que a religión se refiere, la misma vocación evangélica y apostólica a ninguno impide escuchar, en lo que se prueba la autoridad de la doctrina apostólica que a Pablo envió a las naciones, y a Pedro a los judíos ${ }^{59}$.

${ }^{59}$ Schol. conc. Aq., 93: Si confidentiam ullam fidei geritis, aput senatum ipsius urbis fidem continuis triginta uel quadraginta diebus secundum scribturarum omnium auctoritatem conscribtis tractatibus profiteamur, etiam ipsos tractatus nostros auditoribus oblaturi tam eidem urbi publica recitatione pandendos quam etiam ad totius orbis eclesias auditorum relatione per imperiale preceptum mittendos, scituris uobis quod si id placuerit inter cristianos etiam gentilitatis cultores, sed et ueteris legis studiosi audientiae sint athibendi, siquidem etiam ipsa euangelica et apostolica uocatio nullum religioso excipiat auditu, eo quod Paulum quidem ad gentes, Petrum uero ad iudaeos missum apostolice doctrinae probet auctoritas. 
A nuestro entender, la interpretación que efectúa Cracco Ruggini resulta controvertida al menos por dos motivos. En primer lugar, si hubiese sido evidente que en el concilio del 381 Paladio se refería con honorati multi a gentilitatis cultores y a ueteris legis studiosi aquileyenses, cabría esperar que, en su respuesta a la solicitud, Ambrosio hubiese aludido a la inconveniencia de que Iudaei y gentiles juzgaran en cuestiones eclesiásticas. El obispo de Milán, por el contrario, solo alude a laici: «los sacerdotes deben juzgar a los laicos, no los laicos a los sacerdotes» ${ }^{60}$.

Pero, por supuesto, podría haber sucedido que, con honorati multi, Paladio hiciese referencia a ex-magistrados gentiles y judíos de Aquileya pero Ambrosio lo ignorase. Sin embargo, debe notarse que cuando Paladio exigía en su discurso contra el obispo de Milán la participación en el debate de gentilitatis cultores y ueteris legis studiosi no se estaba refiriendo al ya pasado concilio desarrollado en la metrópolis altoadriática sino a un futuro cónclave que deseaba -queda claro- se reuniera en Roma para revisar el caso, lectura que la propia autora sostiene, a partir de la misma documentación, en un trabajo algo posterior ${ }^{61}$. Así pues, nada nos fuerza a concluir que los honorati multi requeridos por Paladio en Aquileya fuesen «dotti pagani» ni «esperti giudaici» como sí lo eran los sujetos cuya presencia se solicitaba para el eventual cónclave romano. Luego, la presencia de judíos entre los magistrados aquileyenses no resulta constatada y la pretendida clave de lectura del discurso cromaciano en lo que a Iudaei respecta se diluye.

\subsection{La epístola ambrosiana}

En su «Ebrei e orientali nell' Italia Settentrionale fra il IV e il VI secolo d. Cr.», de 1959, Cracco Ruggini creía hallar en la epístola LXXIV de Ambrosio de Milán, enviada en el año 388 desde Aquileya a Teodosio I a propósito de la quema de la sinagoga de Callinicon, un testimonio no solo de la existencia de un lugar de culto judío en la ciudad sino también de su destrucción a manos de los cristianos ${ }^{62}$. El fragmento aludido por

${ }^{60}$ Act. conc. Aquil., 680-681: Sacerdotes de laicis iudicare debent, non laici de sacerdotibus.

${ }^{61}$ Cracco Ruggini, 1979, págs. 37-39.

${ }^{62} \mathrm{La}$ adjudicación del incendio a manos cristianas se desprende del hecho de que Cracco Ruggini incluía el episodio entre los acontecimientos en que el conflicto que 
la investigadora es aquel en el cual, amonestando al emperador por haber ordenado la reconstrucción de la sinagoga de Callinicon a costa del obispo de la ciudad, Ambrosio vociferaba:

[...] proclamo que yo hubiese incendiado la sinagoga, que al menos yo se los hubiese ordenado para que no hubiese lugar en el que Cristo fuese negado. Si se me objetase por qué aquí no la incendié, diría que comenzó a ser quemada por el juicio divino, y que cesó mi trabajo ${ }^{63}$.

La interpretación del fragmento ambrosiano reviste una gran importancia, puesto que las lecturas que de él pueden hacerse tienen desiguales e importantes consecuencias para la cuestión que tratamos. Tres circunstancias merecen una particular atención: 1) si efectivamente se trató de un incendio material; 2) dónde habría tenido lugar el incendio; 3 ) a quién cabría imputar su responsabilidad.

En referencia a la historicidad del acontecimiento, cabe señalar que, mientras Cracco Ruggini pensaba en un incendio efectivamente ocurrido en Aquileya, otras lecturas de la epístola ambrosiana niegan al suceso su carácter real. Es el caso de Giovanni Banterle, quien, desde una perspectiva indudablemente distinta, ha sostenido que «non è ben chiaro cosa intenda Ambrogio. Non si tratta, evidentemente, di un incendio materiale, ma piuttosto di un dissolvimento della comunità ebraica per effetto delle numerose conversioni» ${ }^{64}$.

Pero aunque se concediese autenticidad al acontecimiento, otro gran inconveniente está planteado por el referente del pronombre hic. La propia Cracco Ruggini reconocía que no era claro, pudiéndose tratar tanto de Aquileya como de la Italia septentrional en general o de Milán en particular. Sin embargo, concluía que «attenendosi rigorosamente al contesto»

habría enfrentado a cristianos y judíos se había materializado en la parte Occidental del Imperio (Cracco Ruggini, 1959, págs. 200-201 y nota 59; Cracco Ruggini, 1977, págs. 364-366). Más recientemente, sin embargo, la autora ha manifestado una más clara adhesión al carácter fortuito del acontecimiento: «la sinagoga di Aquileia era andata a fuoco spontaneamente ["per volere divino"] poco prima della distruzione di quella di Callinícon nel 388» (Cracco RugginI, 2008, pág. 185).

${ }^{63}$ Ambr., Ep., LXXIV, 8: Proclamo quod ego synagogam incenderim, certe quod ego illis mandaverim, ne esset locus in quo Christus negarentur. Si obiciatur mihi cur hic non incenderim, divino iam cremari coepit iudicio, meum cessavit opus.

${ }^{64}$ BANTERLE, 1988, pág. 91, nota 7. 
correspondía decantarse por la primera alternativa ${ }^{65}$. Muy distinta es la interpretación de Gérard Nauroy, quien no duda en señalar reiteradamente a Milán como sede de un suceso cuya historicidad, por otra parte, parece no compartir ${ }^{66}$.

Por lo que respecta a la autoría del supuesto hecho, si bien las palabras ambrosianas atribuyen la responsabilidad última al diuino iudicio, la autora parecía imputar la acción a la comunidad cristiana local al incluirla, como dijimos, en el listado de episodios de violencia entre cristianos y judíos verificados en Occidente ${ }^{67}$. Françoise Thelamon, por el contrario, sostuvo que la imputación del incendio de la sinagoga local a los cristianos de Aquileya era fruto de una tradición tardía, argumentando que, si así hubiese sido, Ambrosio «n'aurait pas manqué d'en tirer parti» ${ }^{68}$.

En vista de las dificultades que supone la interpretación del pasaje ambrosiano, resulta claro que la presencia de una sinagoga en Aquileya destruida por los cristianos en ocasión de un conflicto con la comunidad judía no resulta evidente a partir de este fragmento, como tampoco, de acuerdo a lo que hemos ya dicho, a partir del registro material.

\subsection{El Sermo XXVIII}

Presentamos a continuación el fragmento del Sermo XXVIII cromaciano al que anteriormente hiciéramos referencia:

De acuerdo al ejemplo terrenal, sin duda muchos corren en el estadio, como dice el Apóstol, pero solo uno recibe la corona, aquel que corre de la mejor manera. De este modo, también en el estadio de la vida presente sin duda corren muchos, pero solo uno recibe la corona. Corren los judíos por la Ley, corren los filósofos por una sabiduría inútil, corren los herejes por un mensaje falso, corren los católicos por la predicación de la fe verdadera. Pero de todos estos

${ }^{65}$ Cracco Ruggini, 1959, págs. 200-201.

${ }^{66}$ Así, por ejemplo, al afirmar que, a juicio de Ambrosio «n'ait pas besoin d'incendier la synagogue de Milan, puisqu'elle est "déjà consumée par le jugement de Dieu"» (NAUROY, 2001, pág. 56. En igual sentido, pág. 40, nota 6 y págs. 47, 55).

${ }^{67}$ Véase la nota 62, supra.

${ }^{68}$ Thelamon, 2001, pág. 98, nota 9. 
solo uno recibe la corona, el pueblo católico que, siguiendo el camino recto de la fe, se dirige a Cristo, y así llega a la palma de la inmortalidad y a la corona ${ }^{69}$.

Estas palabras cromacianas, lo hemos señalado, han sido percibidas como testimonio de la voluntad de nuestro autor de combatir la presencia de un frente tripartito de negadores de Cristo integrado por judíos, herejes y gentiles. Sin embargo, si relativizamos la supuesta connivencia en Aquileya entre estos colectivos en ocasión del concilio desarrollado en la ciudad tras haber observado las dificultades planteadas por la lectura que Cracco Ruggini efectúa de la documentación, el fragmento en cuestión bien puede entenderse como una más entre las varias manifestaciones al interior de los Sermones y del Tractatus in Mathaeum ${ }^{70}$ de la asociación, típica de la literatura antiarriana, entre los herejes y los judíos $^{71}$, a quienes se añaden aquí los philosophi. No hay en el párrafo aludido, por otra parte, ningún elemento que indique la contemporaneidad de los Iudaei, philosophi y haeretici evocados, que remita a su presencia efectiva en Aquileya ni que sugiera el desarrollo de una polémica o de una lucha empírica entre estos y los católicos. En su comentario de 1 Corintios 9, 24, el obispo aquileyense debía dar cuenta de los triunfadores y de los derrotados sugeridos por el texto paulino: ¿quiénes podían integrar este último polo del binomio sino los enemigos de la uera

${ }^{69}$ Chrom., Sermo XXVIII, 8-17: Secundum terrenum exemplum multi quidem, ut ait apostolus, in stadio currunt, sed unus accipit coronam, id est ille qui melius currit; ita et in stadio uitae praesentis, multi quidem currunt, sed unus accipit coronam. Currunt Iudaei per legem, currunt philosophi per inanem sapientiam, currunt et haeretici per falsam annuntiationem, currunt catholici per ueram fidei praedicationem: sed de his omnibus unus coronam accipit, id es populus catholicus qui recto fidei cursu, tendit ad Christum, ut ad palmam immortalitatis coronamque perueniat. En adelante, aludiremos a los Sermones de Cromacio de Aquileya como $S$.

${ }^{70}$ En el mismo sentido, Chrom. Tractatus in Mathaeum XIX, 73-78 (en adelante aludiremos al Tractatus in Mathaeum de Cromacio de Aquileya como Tr.); Tr. XLIII, 29-37; Tr. L, 61-69; Tr. LIII, 150-154; 247-251; S. XXI, 63-67.

${ }^{71}$ Como ha demostrado Raúl González Salinero, la existencia de vínculos doctrinales y conspirativos entre los arrianos y los judíos constituye un tópico de la literatura antiarriana, cuyas bases fueron sentadas por Atanasio de Alejandría (GonzÁlez SALINERo, 2004, págs. 42-43). Su finalidad fue la de asociar al nuevo enemigo, los herejes arrianos, con las ideas teológicas de grupos o movimientos religiosos ya condenados, en este caso el judaísmo, lo que reforzaba extraordinariamente la sanción que sobre el oponente recaía (GonZÁlez SAlinero, 2004, pág. 57). 
fides -judíos, filósofos y herejes-independientemente de su presencia real o no en la ciudad y del hipotético conflicto que pudiesen mantener con la comunidad cristiana?

\subsection{El Sermo XVI}

El contenido del fragmento evocado del célebre Sermo XVI, pronunciado en el marco de una vigilia pascual, es el siguiente:

Gozan los ángeles en el cielo ante la solemnidad de esta vigilia. Gozan los hombres en la tierra. Gozan los mismos poderes infernales, porque también ante ellos llega la tan grande solemnidad de esta noche. A pesar de que los judíos y también los gentiles parezcan todavía ajenos a esta solemnidad, sin embargo no permanecen sin goce, porque son vencidos por una cierta gracia oculta y por el poder del nombre de Cristo que a todos domina. En fin, no pocos entre los gentiles y los judíos gozan la solemnidad de nuestra vigilia como propia de ellos o, si se quiere, con alegría de espíritu si no con el rito de las prácticas religiosas ${ }^{72}$.

Un primer problema se plantea con la localización de los judíos -así como de los gentiles- que supuestamente celebraban la vigilia pascual. Pese a que gran parte de los investigadores que comentaron el Sermo XVI situaron la escena en la Aquileya cromaciana ${ }^{73}$, es necesario señalar que no hay en las palabras del obispo aquileyense un solo indicio a partir del cual se pueda válidamente localizar temporal ni espacialmente a tales sujetos. En consecuencia, a no ser que se explicite por qué este pasaje haría referencia a judíos y gentiles efectivamente presentes en la ciudad, se debería o bien prescindir del Sermo XVI como elemento probatorio de tal circunstancia o, por el contrario, asumir que cada una de las abundan-

${ }^{72}$ S. XVI, 61-69: Gaudent angeli in caelo ad huius uigiliae sollemnitatem. Gaudent homines in terris. Gaudent ipsae infernae potestates, quia et ad ipsas peruenit tanta noctis huius sollemnitas. A qua sollemnitate licet Iudaei adhuc uel gentiles alieni uideantur, non tamen sine gaudio sunt, quia uincuntur occulta quadam gratia ac uirtute nominis Christi qui omnibus dominatur. Denique aliquanti gentilium uel Iudaeorum sollemnitatem huius uigiliae nostrae tamquam propriam celebrant uel laetitia mentis, si non ritu religionis. Un análisis detallado del Sermo XVI de Cromacio de Aquileya en Noce, en prensa (b).

${ }^{73}$ Véase las notas 43-44, supra. 
tes referencias cromacianas a Iudaei y a gentiles, así como a haeretici, se refiere a la coyuntura aquileyense, hipótesis esta última que supone, a nuestro juicio, un despropósito.

Un segundo inconveniente atañe a la acción desarrollada por los $\mathrm{Iu}$ daei y los gentiles del Sermo XVI. Se dice allí que estos sollemnitatem huius uigiliae nostrae tamquam propiam celebrant. ¿Debe entenderse de ello que Iudaei y gentiles, donde fuese que se encontrasen si es que el obispo intentaba referirse a judíos y gentiles concretos, celebraban la vigilia pascual cristiana? ¿O, por el contrario, se dice que alieni uideantur, que «parecen ajenos», porque efectivamente -aunque resultase inconcebible desde la perspectiva cromaciana- no se los veía tomar parte de la festividad, porque mantenían una actitud pasiva y permanecían al margen de ella? El hecho de que se afirme que gozaban de la fiesta cristiana laetitia mentis, si non ritu religionis, sugiere que Cromacio adjudicaba a los judíos y a los paganos una emoción interior carente de correlato externo.

Es posible concluir, en atención a estas observaciones, que el obispo de Aquileya atribuía aquí a los Iudaei y a los gentiles una participación involuntaria e incluso inconsciente en la celebración de la vigilia pascual, de la que no podrían sustraerse dado el carácter cósmico del acontecimiento: el goce se extendía entre los ángeles en el cielo, entre los hombres en la tierra e incluso entre los propios poderes infernales. Si ni siquiera estos podían sustraerse al gozo de la vigilia pascual, menos aún podrían permanecer ajenos los individuos, incluso los judíos y los gentiles. Consecuentemente, desde la óptica cromaciana, tenían que participar, al menos en su fuero interno, sin manifestaciones visibles y -podría añadirse- sin saberlo, de la alegría que para todos los seres significaban las esperanzas salvíficas derivadas de la muerte y la resurrección de Cristo. No debe olvidarse que, por otra parte, la supuesta adhesión de los judíos y de los paganos, enemigos de la Iglesia, a la celebración de la vigilia pascual contribuía a exaltar la santidad de la festividad cristiana ${ }^{74}$.

\footnotetext{
${ }^{74}$ La participación de judíos y paganos en la celebración de la vigilia pascual respondería, así, a la misma dinámica que subyace a los múltiples episodios narrados por las fuentes hagiográficas de acuerdo a los cuales los infideles tomaban parte de los funerales de los santos, doliéndose amargamente ante sus muertes. En efecto, como ha
} 


\subsection{El Sermo XIII}

Resulta adecuado, finalmente, recordar un último fragmento presentado por Rita Lizzi, y anteriormente por Joseph Lemarié ${ }^{75}$, como testimonio de la vitalidad del judaísmo aquileyense durante las décadas finales del siglo IV y las primeras del V. El pasaje del Sermo XIII es el siguiente:

Pero quizá dicen ahora los judíos que están libres de cargas por la sangre de los profetas o por el asesinato de los justos, puesto que ciertamente en ese tiempo ellos no habrían existido. Pero cuando no creen en las palabras de los justos o de los profetas respecto de Cristo, es como si también ellos mismos lapidasen ahora a los justos y matasen a los profetas. Pues, ¿qué mayor injuria de los justos y los profetas puede haber que, al igual que Cristo, no ser creído? Puesto que los judíos no creen en él, sin duda lapidan a los justos, no con las piedras de la calle, sino con la desfachatez de la blasfemia; y matan a los profetas, no con la espada de hierro, sino con el puñal de la perfidia. Porque la blasfemia de los judíos respecto de Cristo es la lapidación de los justos y el asesinato de los profetas. Pero los buenos soldados deben soportar la muerte por su rey. Esto se debe entender respecto de los justos y los profetas, porque son los buenos soldados y los siervos dignos de Cristo. Por ello, sin duda la injuria de Cristo es la lapidación de los justos, y la muerte de estos es la muerte de los profetas. Dijimos esto porque vemos a los judíos también hoy perseguir a los justos y matar a los profetas, porque no creen en las palabras de los justos y de los profetas respecto de Cristo ${ }^{76}$.

sostenido González Salinero, «contamos con suficientes ejemplos como para afirmar que era frecuente en la hagiografía cristiana el topos de los santos que aparecían también "amados" por judíos y paganos. Su significado es evidente: ensalzar la santidad del personaje hasta tal punto que los mismos judíos (y paganos), enemigos declarados de la Iglesia, reconocían su virtud y su bondad» (GonZÁlez SAlinero, 2000, pág. 161, con abundante ejemplos en notas 180 y 181).

${ }^{75}$ Véase la nota 20, supra.

${ }^{76}$ S. XIII, 14-30: Sed dicunt forte nunc Iudaei immunes <se> esse a sanguine prophetarum aut a nece iustorum, quia uero eo tempore non fuerint. Sed cum dictis iustorum uel prophetarum de Christo non credunt, sic est quasi et ipsi nunc lapident iustos et occidant prophetas. Quae enim maior potest esse iniuria iustorum uel prophetarum, quam si Christo non credatur? Cui quia Iudaei non credunt, sine dubio lapidant iustos, non lapidibus uiarum, sed ore blasphemiae; et occidunt prophetas, non gladio ferri, sed stilo perfidiae. Quia blasphemia Iudaeorum in Christo lapidatio iustorum et interfectio prophetarum <sunt>. Sed boni militis pro rege suo mortem suscipere. Quod de iustis uel 
En opinión de Rita Lizzi, en el texto evocado «il riferimento a un gruppo ebraico vivo e fiorente in Aquileia è esplicito» ${ }^{77}$. Tal afirmación resulta desconcertante: indudablemente, el texto evidencia la intención del obispo aquileyense de extender sobre los hijos de Israel de sus propios días -tal como testimonian los adverbios nunc y hodieque- la condena que las Escrituras hacían caer sobre los judíos de tiempos bíblicos y evangélicos a causa de la persecución y la muerte de los profetas y de los justos. Pese a ello, resulta difícil intuir qué elemento del pasaje en cuestión daría cuenta de un colectivo judío vivo y floreciente en Aquileya con el cual el predicador estuviese polemizando. Nos hallamos, a nuestro entender, ante una condena generalizada y atemporal del judaísmo.

El recorrido efectuado evidencia que no resulta adecuado inferir la existencia de un conflicto entre judíos y cristianos en la Aquileya cromaciana a partir de ninguno de los testimonios evocados a tal fin. Del mismo modo, como veremos a continuación, tampoco las restantes alusiones del obispo aquileyense a los judíos dan cuenta de un antagonismo abierto entre ambas comunidades.

\section{IUDAEI EN EL DISCURSO CROMACIANO}

En algunas ocasiones, Cromacio alude a la conversión de judíos al cristianismo, tanto en tiempos evangélicos como en el presente. Sin embargo, tales pasajes son escasos y parecen responder más a las imposiciones derivadas del relato neotestamentario comentado y de las circunstancias históricas que a la propia iniciativa cromaciana. En efecto, si Juan 3, 1-21 daba cuenta de la conversión de Nicodemo, si Juan 11, 1-45 y Hechos de los apóstoles 2, 37-41 aludían al tránsito hacia la fe de algunos elementos judaicos tras la resurrección de Lázaro y a continuación del discurso de Pedro en Pentecostés respectivamente, el obispo debía reflejar en su comentario el contenido fundamental de los acontecimientos narrados, esto

prophetis intellegendum est, quia et boni milites et idonei serui sunt Christi. Vnde, sine dubio, iniuria Christi lapidatio est iustorum, et mors eius mors prophetarum. Hoc ideo diximus, quia uidemus Iudaeos hodieque et iustos persequi, et prophetas occidere, quia dictis iustorum ac prophetarum de Christo non credunt.

${ }^{77}$ Lizzi, 1989, pág. 165. 
es, el hecho de que algunos judíos se habían convertido en tiempos evangélicos $^{78}$; si, como más tarde Petrus ${ }^{79}$, algunos miembros del pueblo de Israel abrazaban el cristianismo en el curso del siglo IV, resultaba natural señalar: «leemos que de la sinagoga muchos se convirtieron y vemos que se convierten cada día al conocimiento de Cristo ${ }^{80} \gg$.

Pese a ello, la imagen que Cromacio de Aquileya transmite respecto del judaísmo y de los judíos es hasta tal punto negativa que su juicio peyorativo emerge incluso al comentar algunas de las conversiones señaladas por las Escrituras. Así pues, como se aprecia en su Sermo XVIII respecto de Nicodemo, el paso a la fe de un judío constituía un acontecimiento singular, incapaz de alterar las consideraciones desfavorables de las que era merecedor el pueblo de Israel en su conjunto: «este Nicodemo, principal de los judíos, deseaba ciertamente venir al Señor, pero temía ofender a los judíos, y por ello vino al Señor no de día sino de noche, porque subsistía todavía en la noche de la ignorancia, en la infidelidad de los judíos»» ${ }^{81}$. Similar apreciación emerge en el Sermo I, donde el aquileyense reprocha que «aunque fuese innumerable la multitud del pueblo de los judíos, viniendo Cristo en la carne, a lo sumo unos pocos creyeron» ${ }^{82}$.

\subsection{Los judíos de tiempos bíblicos y evangélicos}

Las numerosas invectivas que dan forma al discurso antijudaico de Cromacio se nutren de los ya presentados tópicos de la literatura aduer-

${ }^{78}$ S. XXVII, 10-19; Tr. XLVII, 162-173.

${ }^{79}$ Véase nota 54 supra.

${ }^{80}$ Tr. XXXV, 137-138: et de synagoga multos conuersos legimus uel conuerti cotidie ad cognitionem Christi uidemus.... En el mismo sentido Tr. XXXV, 91-92; Tr. XLIII, 153-155.

${ }^{81}$ S. XVIII, 6-10: Nicodemus iste, princeps Iudaeorum, desiderabat quidem ad Dominum uenire, sed Iudaeos timebat offendere, et idcirco ad Dominum uenit non in die, sed in nocte, quia tenebatur adhuc in nocte ignorantiae, in infidelitate Iudaeorum.

${ }^{82}$ S. I, 29-31: cum innumerabilis esset multitudo populi Iudaeorum, adueniente Christo in carne, pauci admodum crediderunt. Podemos pensar, en consecuencia, que el obispo tenía en mente los episodios testamentarios recientemente aludidos cuando se refería a conversiones judías, no remitibles a las Escrituras, en tiempos evangélicos. Tal es el caso de Tr. L A, 20-23, de acuerdo al cual Cristo, tras su muerte, había salvado a muchos tanto ex ipso populo como ex uniuersis nationibus, o en los Tr. XL, 19-32 y Tr. XLVI, 81-93, donde se dice que algunos habían creído provenientes de la Sinagoga. 
sus Iudaeos. Así se observa, por una parte, en los numerosos pasajes de su obra en que las propias Escrituras le imponen reflexionar en torno a la conducta de los miembros del pueblo de Israel en tiempos bíblicos y evangélicos, ocasiones en que, recayendo las diatribas sobre los judíos de antaño, predomina la utilización de tiempos verbales pretéritos.

En efecto, en sintonía con la literatura aduersus Iudaeos, la prédica cromaciana hizo de la historia toda del pueblo judío un relato marcado por la incredulidad y la criminalidad. La falta de fe de Israel se había manifestado, inicialmente, en el rechazo de los justos y de los profetas, tal como recuerda el aquileyense en su comentario del episodio de la transfiguración narrado en Mateo 17, 1-8: «ciertamente, Moisés y Elías [...] contienen la figura de la Ley y de los profetas, quienes también anunciaron la pasión futura del Señor y serán acusadores de aquel pueblo incrédulo, Israel, que ni a Moisés ni a los profetas quiso creer sobre el Hijo de Dios» ${ }^{83}$. Tal como se expresa en el Sermo X al referir a la parábola del banquete nupcial narrada en Mateo 22, 1-14, los profetas y los justos habían padecido la persecución y la muerte a manos de su propio pueblo: «por otra parte, los toros matados para la fiesta de su Hijo aluden a los justos y a los profetas, que fueron asesinados por los judíos porque predicaban que el Hijo de Dios iba a venir y a sufrir en la carne» ${ }^{84}$.

La incomprensión y la conducta criminal que los Iudaei habían manifestado en tiempos veterotestamentarios se reiteraron, de acuerdo al obispo de Aquileya, en relación a Cristo. El aquileyense recurría frecuentemente a verbos como agnosco, suscipio, recipio para insistir sobre el hecho de que los judíos no habían reconocido, no habían recibido, no habían honrado a aquel que les había sido enviado. No creyendo en Cris-

${ }^{83}$ Tr. LIV A, 272-277: Moyses uero et Helias [...] habent figuram legis et prophetarum, qui et futuram passionem Domini nuntiarunt et accusatores erunt populi illius increduli Israhel, qui neque Moysi, neque prophetis de Filio Dei credere uoluerunt. En igual sentido: Tr. IV, 56-68; Tr. L A, 32-34; Tr. LI A, 72-83; Tr. LVIII, 63-67. En S. XXX, 10-13 se dice que la sinagoga «no quiso escuchar a quienes hablaban espiritualmente», acaso los profetas (Vbi synagoga Iudaeorum est, non potest ecclesia nuncupari, quia nec incarnationem Christi credere ex uirgine uoluit, nec spiritaliter praedicantes audire).

${ }^{84}$ S. X, 49-52: Tauros autem occisos propter nuptias Filii sui, iustos et prophetas significat, qui occisi sunt a Iudaeis, quia uenturum ac passurum in carne Dei Filium praedicabant. En el mismo sentido, Tr. LIII, 39-41; S. XIII, 11-13. 
to -afirmaba en el Tractatus LIII- los escribas y los fariseos no habían podido reconocer la luz de la verdad ${ }^{85}$. Fundamento de tal incapacidad era la falta de entendimiento de Israel, tópico al que Cromacio regresa en su Tractatus IV al decir que «uno nació por todos, pero no fue admirado por todos, no fue entendido por todos. Fue entendido por los gentiles, no fue entendido por los judíos. Fue reconocido por la Iglesia, no fue reconocido por la Sinagoga» ${ }^{86}$.

Pero la carencia de fe del pueblo judío respondía, además de a su proverbial incomprensión, a su falta de voluntad. El desconocimiento de la divinidad de Cristo ${ }^{87}$ se explicaba a partir de esta circunstancia, tal como recuerda el autor al decir que «a causa de su corazón apesadumbrado y ciego, los judíos no quisieron comprender ni reconocer a partir de sus virtudes que el Hijo de Dios, a quien veían como un hombre por la figura del cuerpo asumido, era Dios» ${ }^{88}$.

${ }^{85} \mathrm{Tr}$. LIII, 249-250: ueritatis lumen agnoscere non potuerunt, non credendo Christum. En el mismo sentido, Tr. IV, 61-68; Tr. VI, 33-34; Tr. XLIII, 128-129; Tr. XLV, 17-20; Tr. XLIX, 44-46; Tr. LIII, 160-167 (véase la nota 159, infra), 222-225; S. IV, 28-29. En S. XIV, 54-59, finalmente, se dice que el pueblo de los judíos cuestionaba y dudaba sobre la venida de Cristo.

${ }^{86} \mathrm{Tr}$. IV, 65-68: Unus propter omnes natus est, sed non ab omnibus susceptus est, non ab omnibus intellectus est. Intellectus est ab gentilibus, non intellectus a Iudaeis est. Agnitus est ab ecclesia, non est agnitus a synagoga.

${ }^{87}$ Alusiones a la negación de la divinidad de Cristo por parte de los judíos en Tr. XLIV, 49-54; Tr. LI A, 1-24, 41-44 (véase la nota siguiente), 113-116. En el mismo sentido puede entenderse un pasaje del Tractatus XXV en que Cromacio señala que «ciertos infieles o alguien que aún no ha alcanzado el conocimiento de la verdad» hacen mención «de un único Dios Padre creador de todas las cosas», y añade, «como quien ha entrado por el camino de la Ley». Esta última expresión nos permite situar a los judíos entre quienes se referirían solo a la divinidad del Padre (Tr. XXV, 62-71: ut quicumque infidelis uel necdum cognitionem ueritatis consecutus, de uno Deo Patre rerum omnium conditore, uelut per iter legis ingressus...). En Tr. LI A, 78-83, en tanto, se dice que de Christo Domino dubitabant, sin especificar si el objeto de la duda consistía en la divinidad de Cristo o en alguna otra circunstancia.

${ }^{88}$ Tr. LI A, 41-44: Quia grauato et obcaecato corde Iudaei Filium Dei, quem ex forma corporis assumpti hominem uidebat, Deum ex uirtutibus intellegere uel agnoscere noluerunt. Otras referencias a la falta de voluntad de los judíos: Tr. VI, 33-34; Tr. XLIII, 128-129; Tr. XLV, 41-42; Tr. XLIX, 93-95; Tr. L A, 32-34; S. IX, 52-54; 127-128. En Tr. XXXVIII, 35-36; Tr. XXXIX, 40-45; Tr. XLV, 47-50; Tr. XLVII, 99-100; Tr. XLIX, 93-95 se aprecia la falta de voluntad no ya para creer en Cristo sino en sus virtudes, signos y obras. En S. XXX, 10-13 se dice que no quisieron «creer en la encarnación de Cristo 
Cristo, al igual que los profetas y los justos, había sufrido la persecución y la muerte a manos de los judíos. Aludiendo al temor experimentado por Pedro a causa del viento al acercarse a Jesús caminando sobre las aguas, señalaba Cromacio: «¿De qué manera se entiende que, visto el fuerte viento, Pedro temiera sino en referencia a cuando vio la violencia de la persecución que el pueblo de los judíos lanzaba al Hijo de Dios?» ${ }^{89}$. La persecución había derivado en la solicitud explícita de muerte, tal como afirma en su Sermo IX al decir que «con razón, pues, la garganta de los judíos es llamada sepulcro abierto, porque estos abren sus bocas para recibir la muerte del Salvador, diciendo a Pilato: ;crucifícalo, crucifícalo!» ${ }^{90}$. La ocasión permitía al aquileyense identificar a los hebreos con serpentes, pues -en relación al Salmo 5, 10- afirmaba que sus lenguas operaban engaños y había veneno en sus labios ${ }^{91}$. Y si bien en Mateo 27, 27-30 se atribuía a los soldados del procurador romano los suplicios a los que Cristo había sido sometido durante la pasión, Cromacio no perdía ocasión de adjudicar su autoría también a los judíos cuando refería: «así, declaró la presente lectura con qué injurias fue tratado el Señor y Salvador nuestro por los judíos y por los gentiles, a causa de la salvación humana» ${ }^{92}$. La construcción de la imagen peyorativa del pueblo judío en relación a la figura de Cristo culminaba con la aseveración de que los judíos «consideraron de poco valor la pasión del Señor» ${ }^{93}$.

de la Virgen» (Vbi synagoga Iudaeorum est, non potest ecclesia nuncupari, quia nec incarnationem Christi credere ex uirgine uoluit, nec spiritaliter praedicantes audire). De acuerdo a Tr. IV, 60, la misma falta de voluntad habrían mostrado para comprender diuinae legis mysteria.

${ }^{89}$ Tr. LII, 178-181: Quomodo uiso uento ualido timuisse Petrus intellegitur, nisi cum uidit uiolentiam persecutionis quam populus Iudaeorum Dei Filio inferebat? Otras referencias a la persecución operada por los judíos: Tr. XXXV, 122-126; Tr. XLIII, 8485; Tr. LIV, 23-25; S. XIX, 85-86; S. XXV, 65-67.

${ }^{90} \mathrm{~S}$. IX, 82-85: Recte igitur guttur Iudaeorum sepulcrum patens nuncupatum est, quia et ipsi aperiunt os suum, ut mortem exciperent Saluatoris, dicendo ad Pilatum: Crucifige, crucifige! En el mismo sentido, S. IX, 57-60.

${ }^{91}$ S. IX, 85-88: Vnde non immerito etiam serpentes eos <esse > sermo propheticus in psalmo praesenti testatus est: Linguis suis dolose agebant, uenenum aspidum sub labiis eorum.

${ }^{92}$ S. XIX, 13-15: Quibus itaque iniuriis actus sit Dominus et Saluator noster a Iudaeis et a Gentibus, causa salutis humanae, praesens lectio euangelii declarauit.

${ }^{93}$ S. XXIV, 74: uiliorem aestimauerunt Domini passionem. En similar sentido Tr. XLVI, 63-64, donde se hace referencia a qui in uetustate legis gloriantes innouari per passionem Domini noluerunt. 
Pero el desconocimiento del Mesías, a diferencia de lo que sugería Thelamon, no fue más que uno de los tópicos explotados por Cromacio, ya que en las páginas cromacianas encuentran lugar muchas otras acusaciones de índole diversa. En efecto, en tanto que los profetas, los justos y Cristo habían sido objeto de similar descrédito y persecución por parte del pueblo judío, este último había padecido además la blasfemia ${ }^{94}$, el desprecio $^{95}$, la calumnia ${ }^{96}$ y el escándalo ${ }^{97}$ por parte de Israel. En definitiva, como se recuerda en el Tractatus L en relación a los fariseos, los judíos «se mostraron al Señor como enemigos y adversarios» ${ }^{98}$. Por otra parte, del mismo modo que la tradición aduersus Iudaeos en que su discurso se enraizaba, el obispo apelaba a una serie de deficiencias físicas y cognoscitivas judaicas para explicar el desconocimiento del Mesías: la acusación de incredulitas $^{99}$ y de error $^{100}$, se fundaba en la ignorantia ${ }^{101}$, en la stultitia $^{102}$, en la insipientia ${ }^{103}$, en la caecitas $^{104}$, en el cor lapideum ${ }^{105}$, grauatus

${ }^{94}$ El tópico de la blasfemia contra Cristo emerge en Tr. XLIX, 100-103, 124-127 y en Tr. L, 96-103. En Tr. XLV, 17-20, en tanto, Cristo es acusado de blasfemia por los fariseos y los doctores de la ley.

${ }^{95} \mathrm{Tr}$. XXXV, 135-136: contempto bonitatis ipsius ac pietatis auctore, diabolum principem malitiae est secuta. En el mismo sentido, Tr. IV, 77-79; Tr. XLV, 60-62, 95-99; Tr. LVII, 103-107; S. XXIV, 72-73. Aún cuando no se recurre al verbo contemno, similar idea de desprecio se da en S. XXIV, 59-60, donde se dice que «nuestro Señor y Salvador fue vendido por los judíos, fue adquirido por los gentiles» (Dominus ac Saluator noster distractus a Iudaeis, comparatus est a gentibus).

${ }^{96} \mathrm{~S}$. XXIV, 88-89: Dominus a synagoga saepe calumniis appetitus est. En igual sentido, Tr. XLIX, 44-46.

${ }^{97} \mathrm{Tr}$. LV, 108-111: Quam sententiam molae asinariae maxime in populo Iudaeorum impletam agnoscimus, qui cum saepe scandalum aduersus Dominum et aduersus eius apostolos excitarent.

${ }^{98} \mathrm{Tr}$. L, 64-65: inimici et aduersarii Domino exstiterunt.

${ }^{99}$ Tr. X, 73-74; Tr. XL, 58-59; Tr. XLI, 85-86, 246-256; Tr. XLIV, 41-42; Tr. XLVII, 93-96, 191-192, 211-215; Tr. XLIX, 124-127; Tr. L A, 10-11; Tr. LI A, 6-9, 72-75, 102-104, 125-127; Tr. LIII, 247-250; Tr. LIV A, 275-277; S. IV, 54-56; S. XXVII, 45-57, 126-128.

${ }^{100}$ S. XXXII, 77-79; S. XXXIII, 81-85.

${ }^{101}$ Tr. LI A, 80-82, 98-99; Tr. LV, 115-118; S. XVIII, 9-10.

${ }^{102}$ S. IX, 7-8, 46-60.

${ }^{103}$ S. IX, 46-48.

${ }^{104}$ Tr. XLVIII, 56-58; Tr. XLIX, 44-46, 57-58; Tr. L A, 10-11; Tr. LIII, 247-249.

${ }^{105}$ S. IV, 67-69. 
y obcaecatus $^{106}$, en la dementia ${ }^{107}$, en la mens sacrilega ${ }^{108}$ y polluta ${ }^{109}$, en la os impium ${ }^{110}$, en la conscientia polluta ${ }^{111}$ de Israel.

Hay también lugar en el corpus cromaciano para toda una serie de acusaciones antijudaicas de contenido estrictamente religioso. Los judíos eran reos de infidelitas ${ }^{112} \mathrm{y}$, mostrándose como transgressores legis ${ }^{113}$, habían permanecido en la vetusta litterae ${ }^{114}$, habían olvidado la diuina religio y la fides ${ }^{115}$. Carentes de disposición para la vida espiritual, conformaban un pueblo rudis et durus ${ }^{116}$, insolens ${ }^{117}$, terrenus et carnalis $^{118}$. Siendo así, los líderes espirituales y las instituciones religiosas judías habían siempre sido vanas: los doctores de los judíos eran «malvados e inútiles pastores que se perdieron tanto a sí como a las ovejas del Señor» ${ }^{119}$; los ancianos y los sacerdotes de la ley «no pudieron proporcionar la salud de la salvación al mismo pueblo» ${ }^{120}$; escribas y fariseos, olvidada la ley divina, no plantaban los mandatos de Dios sed sua potius mandata ${ }^{121}$, por lo que alios secum in

${ }^{106}$ Tr. LI A, 41-43.
${ }^{107}$ Tr. XLIX, 44-46, 78-79.
${ }^{108}$ Tr. XLIX, 100-103.
${ }^{109}$ Tr. LIII, 41-43.
${ }^{110}$ Tr. XLIX, 100-103.
${ }^{111}$ Tr. LIII, 38-41.
${ }^{112}$ Tr. VII, 23-24; Tr. XXIV, 74-75, 90-91; Tr. XXXVIII, 23-24; Tr. XLI, 246-256; Tr. XLV, 34-37, 57-59; Tr. XLVII, 211-215; Tr. XLIX, 44-46; Tr. LI A, 6-7, 22-24, 8083, 94-98, 113-116, 125-126; Tr. LIII, 152-154, 227-228; S. IX, 7-8; S. XVIII, 9-10; S. XXXII, 73-78.

113 Tr. LIII, 50-54; Tr. LIX, 130-132; S. III, 71-72.

114 Tr. XLVI, 51-55, 62-74, 114-125.

${ }^{115}$ S. IV, 8-9.

116 Tr. XXI, 7-10.

117 Tr. XXV, 10-12.

${ }^{118}$ Tr. XXVI, 13-14.

${ }^{119}$ S. XXXII, 95-96: doctores Iudaeorum mali et inutiles pastores, qui et se et oues Domini perdiderunt.

${ }^{120}$ Tr. XLVII, 155-158: maiores populi et sacerdotis legis [...] nullam tamen sanitatem salutis eidem populo praestare potuerunt.

${ }^{121}$ Tr. LIII, 232-234. 
mortis foueam attraxerunt ${ }^{122}$. La Sinagoga, que «languidecía abrumada a causa de los graves delitos como por ciertas fiebres» ${ }^{123}$, que «era conducida por diversos espíritus impuros» ${ }^{124}$, filios procreauit inutiles ${ }^{125}$.

Esta incompetencia para la vida religiosa podría explicar la denuncia cromaciana de la inclinación judía hacia los placeres mundanos. El obispo acusaba al pueblo de Israel de ser propenso a la luxuria ${ }^{126}$, a los uitia corporalia ${ }^{127}$, a los carnalis effrenata uoluptas $^{128}$, a la intemperantia gulae $^{129}$, actitudes comprensibles en el marco de la passiua Iudaeorum licentia ${ }^{130}$. El comentario de Mateo 5, 20 le permitía, además, reprochar a los Iudaei su empecinada búsqueda de la gloria terrenal:

[...] se reprende la justicia de los escribas y de los fariseos, porque no buscaban la fe de la promesa divina sino la alabanza humana y la gloria del siglo [...]. Los escribas y los fariseos mantenían, luego, una apariencia de la justicia, no para agradar a Dios, sino para obtener la fama de la gloria humana, para adquirir beneficios terrenos y provechos temporales $^{131}$.

A lo largo de los Sermones y del Tractatus in Mathaeum se encuentran algunas referencias al tópico de la malitia $^{132}$ y de la iniquitas ${ }^{133}$ judías, así

${ }^{122}$ Tr. LIII, 247-250.

${ }^{123}$ Tr. XL, 20-21: quae delictis grauibus uelut quibusdam febribus oppressa languebat. En Tr. XL, 37-41 se vuelve sobre los delicta populi Iudaeorum.

${ }^{124}$ Tr. LIV, 29-30: synagoga [...] diuersis immundis spiritibus agebatur.

${ }^{125}$ S. XXXIII, 114-116.

126 Tr. LIII, 103-105.

${ }^{127}$ S. XXXIII, 81-85.

${ }^{128}$ Tr. XXIV, 8-10.

${ }^{129}$ Tr. LIII, 103-105, 110. En Tr. LIII, 119-121, en tanto, se dice que bien merecían las prohibiciones alimenticias que se les habían impuesto qui mannae caelesti carnes Aegypti, et cucumeres ac pepones praeferebant.

${ }^{130}$ Tr. XXIV, 21-22.

${ }^{131}$ Tr. XX, 61-69: Reprehenditur iustitia scribarum et pharisaeorum, quia non fidem promissionis diuinae, sed humanam laudem et saeculi gloriam quaerebant [...] Retinebant ergo speciem iustitiae scribae et pharisaei, non ut Deo placerent, sed ut famam humanae gloriae quaererent, ut lucra terrena et temporalia commoda mercarentur.

${ }^{132}$ Tr. XLIX, 57-58; S. XXXII, 95-96.

${ }^{133}$ Tr. VI, 34-37; Tr. XLIX, 57-58, 65-67, 73-75, 85-87; S. X, 53-54; S. XXXI, 51-52. 
como también abundantes alusiones a su condición de pecadores. Esto último puede ilustrarse a partir del Tractatus XLV, donde se recuerda que, en Jeremías 8, 21-23, el profeta había increpado «al pueblo que, herido por los pecados, despreciando al autor de la medicina celeste, no quiso recibir la salud de la salvación» ${ }^{134}$.

Acaso todas estas acusaciones que hacía recaer sobre los judíos del pasado, a las que pueden aún añadirse la perfidia ${ }^{135}$, la impietas ${ }^{136}$, la $s u$ perbia $^{137}$, condujesen al obispo a refrendar la existencia del vínculo, ya denunciado por la literatura patrística, entre el demonio y el pueblo de Israel. En efecto, afirmaba que entre ambos existía una relación de filiación: «quienes desde hace tiempo fueron llamados hijos de Dios, son llamados ahora raza de víboras a causa de sus crímenes, porque haciendo la voluntad del diablo, que al comienzo es llamado "serpiente", aquellos se hicieron hijos del diablo» ${ }^{138}$. En el Tractatus L A, en tanto, afirmaba respecto de los Iudaei; «aquellos no eran hijos de Abraham, sino hijos del diablo» ${ }^{139}$. El pueblo judío, recordaba, siguió al demonio ${ }^{140}$, fue hecho su prisionero $^{141}$, se dejó conducir por él ${ }^{142}$.

Previsiblemente, se reitera en la obra del aquileyense el tópico de la condena eterna de los judíos. Los hijos de Israel «rechazaron el don de

${ }^{134}$ Tr. XLV, 60-62: Quo dicto increpat populum qui medicinae caelestis auctorem contemnens, uulneratus peccatis, sanitatem salutis accipere noluit. Otras referencias a la pecaminosidad judía en Tr. X, 37-41; Tr. XVIII, 56-59; Tr. XLV, 34-38, 72-74; Tr. XLVI, 67-74, 122-125; Tr. XLVII, 99-100; Tr. LIII, 41-43; S. IX, 69-70; S. XXXIII, 81-85.

135 Tr. X, 70-71; Tr. XXIV, 74-75; Tr. XL, 58-59; Tr. XLIV, 21-24; Tr. XLVI, 76-77; Tr. LI A, 98-100; S. IV, 54-55; S. IX, 124-125; S. XXI, 66-67.

136 Tr. XLIII, 29-33; Tr. XLIV, 41-42, 51-53; Tr. XLIX, 65-67.

137 Tr. X, 50-51; Tr. XLIV, 70-72; Tr. XLV, 34-38; Tr. LVII, 104-107.

${ }^{138}$ Tr. X, 28-31: Qui iamdudum filii Dei dicti sunt, nunc merito criminum dicuntur progenies uiperarum, quia faciendo diaboli uoluntatem, qui ab initio serpens est appellatus, ipsi se filios diaboli constituerunt. Es claro que el adverbio nunc no remite en este caso al tiempo presente sino a la situación pretérita a la que se hace referencia.

139 Tr. L A, 5-6: Generatio mala et adultera dicendo ostendit illos non esse filios Abrahae, sed filios diaboli. Nos inclinamos por el uso del pretérito en la traducción puesto que es Jesús quien pronuncia la frase en referencia a los judíos de su tiempo.

140 Tr. XXXV, 135-136.

141 Tr. XLIII, 61-68.

142 Tr. XLIII, 147-151. 
la gracia tan grande que se les había ofrecido», esto es, la salvación ${ }^{143}$. Y puesto que «a esta Vida [Cristo] el pueblo de los judíos no quiso creer, se precipitó en la muerte, porque quien escapa a la vida inevitablemente se precipita en la muerte» ${ }^{144}$. Tal noción, reiterada insistentemente a lo largo del Tractatus in Mathaeum y de los Sermones, se aprecia más claramente que en ningún sitio en el comentario del episodio sobre la resurrección de la hija de Jairo, narrado en Mateo 9, 23-26:

En los flautistas y en la muchedumbre alborotada que se burlaban del Señor que decía «la niña no está muerta, sino que duerme», entendemos indicados a los principales de la sinagoga y a la multitud del pueblo de los judíos quienes, cuando escucharon que era prometida a los gentiles la esperanza de la vida eterna por el Hijo de Dios, tuvieron para la risa y el desprecio tan grande gracia del Señor. No sin razón mandó el Señor que estos fuesen echados fuera, para que se mostrase que semejantes hombres incrédulos e infieles debían ser completamente excluidos de la promesa de la vida eterna y del reino por quien es el autor de la vida y el Señor del reino celeste ${ }^{145}$.

En similar sentido, se afirma en otros pasajes cromacianos que los escribas y los fariseos nec curam salutis accipere meruerunt ${ }^{146}$ y que la generatio mala et adultera Iudaeorum, «no mereció recibir en la frente

${ }^{143}$ S. XII, 6-12: Neque enim fas erat, ut propter unam tantum gentem saluandam, Filius Dei de caelo descenderet, qui omnes gentes creauit. Delatum est primum quidem Iudaeis merito patriarcharum, ex quorum genere descendebant. Sed quia oblatum sibi munus tantae gratiae respuerunt, diuersis gentibus ac nationibus salus ipsa donata est. Otras referencias al rechazo judío de la salvación ofrecida por Cristo: Tr. XVIII, 54-59; Tr. XLV, 60-62; Tr. LIII, 36-38; Tr. LIV, 13-15; S. X, 61-65; S. XIV, 50-54.

${ }^{144}$ S. XVII, 9-11: Cui uita Iudaeorum populus credere noluit, atque ideo mortem incurrit, quoniam qui uitam refugit mortem incurri necesse est. En el mismo sentido, S. XVII, 36-38.

${ }^{145}$ Tr. XLVII, 206-215: In tibicines autem et turbam tumultuantem, qui Dominum irridebant dicentem: Non est mortus puella, sed dormit, principes synagogae et turbam populi Iudaeorum intellegimus demonstratam, qui cum a Filio Dei spem uitae aeternae promissam gentibus audirent, tantam gratiam Domini, risui ac contemptui habuerunt. Quos non immerito iussit Dominus foras expelli, ut ostenderet huiusmodi homines incredulos et infideles, a promissione uitae aeternae uel a regno Dei esse penitus excludendos, ab eo qui auctor uitae et Dominus regni caelestis est.

146 Tr. XLV, 47-50. 
el signo de la cruz, el único que fue dado a los creyentes para la salvación» ${ }^{147}$.

\subsection{Los judios del presente}

Una abundante cantidad de invectivas antijudaicas difieren por su naturaleza respecto de las que hasta aquí hemos considerado. Muchas de ellas emergen en la lectura alegórica que de distintos fragmentos escriturarios realiza el obispo. Construidas a partir del tiempo verbal presente y conteniendo, en algunos casos, adverbios que denotan contemporaneidad, nuestra posibilidad de aproximarnos al pensamiento de Cromacio respecto del judaísmo y de los judíos en sus propios tiempos parecería depender de este tipo de referencias. Sin embargo, como veremos, es muy poco lo que en tal sentido nos dicen, puesto que estas imprecaciones, como aquellas referidas a los judíos del pasado, recurren también a los tópicos de la literatura aduersus Iudaeos.

En efecto, como hemos ya señalado, el aquileyense denuncia la perpetuidad del desprecio y de la acción homicida antaño propinada por los miembros del pueblo judío a los profetas y a los justos, haciendo reos de la misma culpa a los judíos de su propio tiempo ${ }^{148}$. Como en este caso, el obispo actualiza en su Tractatus XLIII otros importantes tópicos de la literatura patrística, aquellos referidos a la impietas judía y a la negación de Cristo. En efecto, en referencia al reconocimiento de Jesús como el «Hijo de Dios» por parte de los endemoniados gadarenos, señala:

Y puesto que consta esta tan manifiesta declaración de los demonios acerca del Hijo de Dios, ¿cuál es la impiedad de los judíos o cuál la tan grande demencia de los herejes al querer negar al Hijo de Dios que los demonios no pueden negar? ¿Acaso no serán condenados con justa sentencia todos los negadores del nombre divino en el

${ }^{147}$ Tr. LIV, 2-5: Generatio mala et adultera Iudaeorum dum signum de caelo ostendi sibi infideliter quaerit, signum crucis quod solum ad salutem credentibus datum est, accipere in fronte non meruit. La condena de los judíos del pasado reaparece en Tr. L, 96-103; Tr. L A, 71-77; Tr LIII, 227-238; Tr. LV, 108-118; Tr. LIX, 130-136; S. XIV, 20-22.

${ }^{148}$ Véase nota 76, supra. 
juicio futuro no ya por las palabras proféticas y evangélicas sino por la misma confesión de los demonios? Ningún perdón, en efecto, merecerán entonces quienes lo desconozcan, negando al Hijo de Dios, a quien no negaron ni los autores de la misma negación ${ }^{149}$.

De igual manera, la blasfemia judaica reaparece al señalar que los judíos lapidan a los profetas ore blasphemiae, y que la blasphemia Iudaeorum in Christo es la lapidación de los justos y el asesinato de los profetas $^{150}$. Lo propio ocurre con el scandalum. Ciertamente, en su comentario de Mateo 18, 6, «al que escandalice a uno de estos pequeños que creen en mí, más le vale que le cuelguen al cuello una de esas piedras de molino que mueven los asnos y le hundan en lo profundo del mar», el obispo de Aquileya escribe:

En esto vemos representado principalmente al judío, quien sufre escándalo por causa de la cruz de Cristo y por la predicación de su nombre. Para este tal sería mejor si habitase en la ceguera del error de los gentiles como sumergido en lo profundo del mar que, bajo la predicación de la ley -por la cual el judío cree conocer la luz de la verdad- sufrir escándalo por Cristo o por sus apóstoles, a los que llama «pequeños». Porque más fácil es que el gentil sin la Ley no crea en Cristo que el judío, que vive bajo la Ley, niegue al señor de la misma Ley ${ }^{151}$.

En su Tractatus XIX, comentando Mateo 5, 14-16, vos estis lux mun$d i$, emerge una basta nómina de inculpaciones vinculadas con las carencias cognoscitivas judías que, habiendo impedido el reconocimiento del

${ }^{149}$ Tr. XLIII, 29-37: Et cum daemonum haec sit de Dei Filio tam manifesta professio, quae impietas Iudaeorum est, uel quae haereticorum tanta dementia negare Dei Filium uelle, quem daemones negare non possunt. Nonne iusto iudicio omnes diuini nominis negatores in futuro iudicio non iam propheticis uel euangelicis uocibus sed ipsa confessione daemonum damnabuntur? Nullam enim iam ignorandi ueniam merebuntur negando Dei Filium quem auctores negationis ipsius non negarunt. Similar acusación en Tr. LV, 97-105 (véase nota 151, infra).

${ }^{150}$ Véase nota 76, supra.

${ }^{151}$ Tr. LV, 97-105: In quo maxime Iudaeum significare uidetur, qui de cruce Christi, ac de praedicatione nominis eius scandalum pati cognoscitur. Huic ergo tali expediret, si in caecitate erroris gentilis ueluti in profundum maris demersus uersaretur, quam sub praedicatione legis, per quam se lumen ueritatis agnoscere Iudaeus existimat, de Christo uel apostolis eius, quos paruulos appellat, scandalum pateretur; quia facilius est gentilem sine lege Christo non credere, quam Iudaeum sub lege uiuentem, legis ipsius dominum denegare. 
Mesías en tiempos evangélicos, como hemos visto, conducían al judío al error en la actualidad. La lux Spiriti, señalaba el autor,

[...] no debe ser cubierta ni oscurecida con el velo de alguna inteligencia ciega, como hacen los judíos o los herejes, quienes se esfuerzan por cubrir y ocultar la luz transparente de la predicación divina con falsas interpretaciones, predicando la perfidia en lugar de la fe y velando la luz de la verdad con las tinieblas del error ${ }^{152}$.

La infidelitas judía era proyectada hasta el presente en el Tractatus XXIV, cuando el aquileyense, en referencia a la prohibición de jurar pronunciada por Jesús de acuerdo a Mateo 5, 33-37, decía: «Hallamos, es cierto, que algunas veces Dios jura, pero a causa de la incredulidad de los hombres y principalmente por la perfidia de la infidelidad de los judíos, quienes piensan que toda verdad se basa en la fe del juramento» ${ }^{153}$. Como en este pasaje, la perfidia del pueblo de Israel se actualizaba en los ya evocados Tractatus XIX ${ }^{154}$ y Sermo XIII ${ }^{155}$.

El Tractatus LIII presenta una gran cantidad de invectivas antijudaicas que responden a las características ahora consideradas. Inicialmente, se insistía sobre la incapacidad judía para la vida espiritual y su contraparte, el afecto por la vida terrenal. En efecto, en referencia a las palabras de Isaías pronunciadas por Jesús para increpar a los fariseos y escribas que inculpaban a los discípulos por no lavarse las manos antes de tomar alimento, añadía Cromacio que los judíos «ciertamente sin motivo simulan venerar a Dios, a quien honran con los labios más que con el corazón, y a cuyos preceptos divinos y salvadores prefieren las doctrinas y los mandatos de los hombres» ${ }^{156}$. Más adelante, junto a un tópico de la litera-

${ }^{152}$ Tr. XIX, 74-78: quod non aliquo caecae mentis uelamine operiendum est uel obscurandum, ut Iudaei uel haeretici faciunt, qui perspicuam lucem praedicationis diuinae prauis interpretationibus obtegere et occultare nituntur, pro fide perfidiam praedicando, et lumen ueritatis erroris tenebris obuelando.

${ }^{153}$ Tr. XXIV, 73-76: Inuenimus quidem aliquoties Deum iurantem, sed propter hominum incredulitatem maximeque propter iudaicae infidelitatis perfidiam, qui putant omne uerum nonnisi in fide iuramenti consistere. Se alude a la infidelitas mosaica también en Tr. LIII, 181-187 (véase nota 160, infra).

154 Véase nota 152, supra.

155 Véase nota 76, supra.

156 Tr. LIII, 66-69: Vere enim sine causa Deum se colere simulant, quem labiis magis quam corde honorant, et cuius praeceptis diuinis ac salutaribus doctrinas et mandata 
tura aduersus Iudaeos al que hemos ya hecho referencia en alusión a los Iudaei de tiempos bíblicos y evangélicos -la caracterización del pueblo judío contemporáneo como peccator ${ }^{157}$-, sale a la luz una extensa nómina de acusaciones cromacianas de carácter atemporal. En efecto, explicando el simbolismo de las prohibiciones alimenticias contenidas en Levítico 11 y Deuteronomio 14, 3-21, se establecía un vínculo entre los católicos y los animales terrestres puros, es decir, los rumiantes con pezuña hendida:

[...] hender la pezuña es tener los preceptos de los dos Testamentos, como dijimos, en una única raíz de la fe, o bien ciertamente confesar al Padre y al Hijo en unidad de naturaleza. Rumiar, por otra parte, como dijimos, es cultivar siempre las palabras divinas, darles vueltas como alimento celeste en la boca y en el corazón en continua meditación ${ }^{158}$.

Los judíos, en tanto, eran equiparados al animal impuro, puesto que no satisfacían estas dos conductas:

[...] rumiar y no hender la pezuña, es propio de los judíos quienes, aunque tengan siempre en la boca los preceptos de la Ley, sin embargo, puesto que no hienden las pezuñas, es decir, puesto que no reciben los dos Testamentos ni confiesan al Padre y al Hijo, también ellos mismos son contados por el Señor entre los animales impuros, pues conservando solo el Antiguo Testamento como una única pezuña, no caminan con pie firme sino con pasos resbaladizos ${ }^{159}$.

hominum praeferunt.

${ }^{157}$ En Sermo XXV, 48-50 Cromacio señala: «así pues, los judíos suponen que hay que mantenerse lejos de los alimentos impuros, pero jamás son puros, porque están colmados de la impureza de los pecados» (Denique Iudaei ab escis putant immundis abstinere, sed nunquam mundi sunt, quia immunditia peccatorum pleni sunt ). El tópico referido a la condición pecaminosa de los Iudaei reaparece en Tr. XLV, 72-74; Tr. XLVII, 99-100; Tr. LIII, 181-187 (véase la nota 160, infra).

${ }_{158}$ Tr. LIII, 145-149: Findere enim ungulam est aut praecepta duorum testamentorum, ut diximus, in una fidei radice tenere, aut certe Patrem et Filium confiteri in unitate naturae. Ruminare uero est, ut diximus, recolere sempre uerba diuina, eaque tamquam cibum caelestem in ore atque in corde continua meditatione reuoluere.

${ }^{159}$ Tr. LIII, 160-167: Ruminare uero et ungulam non findere, Iudaeorum est, qui, licet praecepta legis semper in ore habeant, tamen, quia ungulas non findunt, id est quia neque duo testamenta recipiunt, neque Patrem et Filium confitentur, etiam ipsi inter immunda animalia a Domino reputantur, dum uetus tantum testamentum tamquam singularem ungulam retinentes, non firmo gradu, sed lubricis gressibus ambulant. 
Poco después, el aquileyense interpretaba la figura oculta tras la imagen de los peces impuros, diciendo:

En estos peces que no tienen ni escamas ni aletas, reconocemos representados a los judíos quienes, a pesar de que se sumerjan diariamente y, como los peces, nunca se alejan del agua, puesto que no tienen escamas ni aletas, es decir, porque no reconocen sus pecados de infidelidad ni son conducidos por el auxilio de la fe, sin embargo no pueden aprovecharse de la gracia celeste y espiritual ${ }^{160}$.

Así pues, emergen en el Tractatus LIII distintas inculpaciones: se acusa a los judíos de no aceptar los dos Testamentos, de no confesar al Padre y al Hijo en unidad de naturaleza -lo que implica, nuevamente, desconocer la divinidad de Cristo- de ser pecadores, infieles y ajenos a la fe.

Digamos finalmente que algunos pasajes de la obra cromaciana, de acuerdo a la temporalidad verbal empleada, nos permiten apreciar que su autor también extendía a los judíos de sus propios tiempos la condena a la muerte eterna que la literatura patrística había hecho recaer sobre sus semejantes de antaño. Ciertamente, en su lectura alegórica del episodio de los endemoniados gadarenos, indicaba:

[...] en los pastores de los cerdos que, visto el signo de la virtud divina, escaparon a la ciudad anunciando lo que había sucedido, de modo que pidieron al Señor que se alejara de sus territorios, se muestra la imagen de los principales de los judíos y de los sacerdotes de los ídolos quienes, suministrando a los hombres impuros e infieles los pastos de su error y de su infidelidad, los alimentan como cerdos para la muerte perpetua ${ }^{161}$.

${ }^{160}$ Tr. LIII, 181-187: In his autem piscibus qui nec squamas habent nes pennas, Iudaeos intellegimus significatos, qui, licet cotidie baptizentur, et tamquam piscis, numquam de aqua recedant, tamen, quia nec squamas habent, nec pennas, id est quia nec infidelitatis sua peccata cognoscunt, nec auxilio fidei gubernantur, in usu caelestis et spiritalis gratiae haberi non possunt.

${ }^{161} \mathrm{Tr}$. XLIII, 94-101: In pastoribus autem porcorum qui uiso signo diuinae uirtutis fugerunt nuntiantes in ciuitate quae gesta sunt, ita ut rogarent Dominum ut discederet a finibus eorum, principum Iudaeorum uel sacerdotum idolorum typus ostensus est, qui hominibus immundis et infidelibus erroris et infidelitatis suae pabula ministrantes, eosdem uelut porcos ad mortem perpetuam nutriunt. De igual modo, en el Tr. LIV A, 328-333 señala Cromacio: «por lo cual a no ser que cada uno de nosotros asuma fielmente bajo una única proclamación de la fe tanto a Moisés, esto es la Ley, como a Elías, esto es el mensaje 


\section{CONCLUSIÓN}

Al comenzar este trabajo nos propusimos aprehender la razón de ser del discurso marcadamente antijudaico de Cromacio de Aquileya. De acuerdo a lo expuesto, la hipótesis del conflicto no logra dar cuenta del fenómeno, puesto que el requisito fundamental de tal teoría, esto es, la existencia de conflicto entre la comunidad de judíos y la de cristianos, no puede corroborarse en la metrópolis altoadriática durante el período cromaciano a través de la documentación existente, sea material que literaria. En consecuencia, en el estado actual de nuestros recursos heurísticos, tal propuesta debe ser desestimada.

Por otra parte, la invectiva del aquileyense contra los judíos del pasado y del presente incorpora tópicos como la atribución de deficiencias físicas y mentales, de incapacidad para la vida religiosa, de excesos sexuales y alimenticios, de amor por el mundo y, en algún caso ${ }^{162}$, de características zoológicas. De tal modo, a diferencia de cuanto sostuvo Thelamon, resulta claro que el obispo trasciende largamente la denuncia del desconocimiento judaico de la divinidad de Cristo y sus consecuencias, es decir, el extravío de Israel, instrumentos con los que se habría pretendido confortar a la propia comunidad cristiana.

Por nuestra parte, creemos que es precisamente en este punto, en la constitución de la comunidad cristiana aquileyense, donde reside la clave interpretativa del discurso antijudaico cromaciano. Ciertamente, aún cuando el cristianismo había alcanzado a la ciudad al menos desde los tiempos de Constantino ${ }^{163}$, la cristianización de Aquileya era, para

profético, y a los apóstoles, es decir, la predicación evangélica, no podrá reinar con el Hijo de Dios en aquella gloria celeste» (Quapropter nisi unusquisque nostrum fideliter et Moysen, id est legem, et Heliam, hoc est propheticam annuntiationem, et apostolos, id est euangelicam praedicationem, sub una fidei praedicatione susceperit, cum Filio Dei in illa caelesti gloria regnare non poterit). En atención al ya apuntado rechazo mosaico al Nuevo Testamento (véase nota 159, supra), parece claro que el obispo insiste en esta ocasión sobre la incapacidad de los judíos para alcanzar la salvación.

162 Véase nota 91, supra.

${ }^{163}$ Dan cuenta de la existencia de una comunidad cristiana la construcción, en torno al año 320, del complejo debido al obispo Teodoro (la producción académica al respecto es muy extensa: remitimos a la síntesis efectuada por Giuseppe Cuscito [Cuscito, 2009, págs. 110-113], con abundante bibliografía; especial atención merece Sotinel, 2005, págs. 72-89] así como también unos pocos epitafios, entre la escasa cantidad datable, en que 
las décadas finales del siglo IV y las primeras del V, una empresa aún en desarrollo. Los testimonios arqueológicos y epigráficos muestran que la nueva fe se hallaba escasamente representada en la topografía urbana ${ }^{164}$, que el compromiso de la aristocracia local con el cristianismo fue hasta entonces menor ${ }^{165}$, que no se habían desarrollado todavía espacios cementeriales específicamente cristianos, recibiendo sepultura los adeptos a la fe de Cristo en los áreas tradicionalmente utilizadas a tal fin ${ }^{166}$. Complemento de esta circunstancia, como ha indicado Monika Verzár-Bass, algunos cultos precristianos mantenían su vitalidad en la metrópolis ${ }^{167}$, en tanto que a $25 \mathrm{kms}$ de distancia, en la desembocadura del río Timavo, un mitreo continuó en funciones al menos hasta los años del episcopado cromaciano $^{168}$. Siendo así, y en atención a las advertencias lanzadas por Cromacio hacia los cristianos que continuaban comportándose al modo de los corui $^{169}$ y a su insistencia respecto de la conveniencia de que los católicos celebrasen el año nuevo en coincidencia con la Pascua y no en enero, como los gentiles ${ }^{170}$, puede concluirse que las implicaciones de la asunción del cristianismo no siempre habrían estado lo suficientemente claras para el conjunto de los neófitos aquileyenses. En este sentido,

algunos individuos expresaron su aceptación de la nueva fe al momento de su muerte en el curso del siglo IV (FerRua, 1994, págs. 163-164; Cuscito, 2002, págs. 258-259; Sotinel, 2005, págs. 91-93; VERGONE, 2007, pág. 32). En el mismo sentido, se debe recordar que en tiempos del obispo local Valeriano existía en la ciudad un seminarium del que formaron parte importantes personalidades eclesiásticas del momento, entre los cuales Cromacio, Rufino de Concordia y Jerónimo de Estridón (Scholz, 1970). Para la difícil cuestión del cristianismo aquileyense preconstantiniano, véase BRATOž, 1999.

${ }^{164}$ El debate en torno a la datación de las basílicas cristianas de Aquileya durante la Antigüedad Tardía es arduo. Véase en general, con abundante bibliografía, BERTACCHI, 1980, págs. 99-264; Cusciтo, 2009, págs. 107-148. A favor de una cronología tardía para el desarrollo de la topografía cristiana aquileyense, Sotinel, 2005, págs. 262-270; CANTINO Wataghin, 2006, págs. 306 y 312-314; Cantino Wataghin, 2008, págs. 346-350.

${ }^{165}$ Sotinel, 2005, págs. 97-104; Pietri, 1982, págs. 127-134.

${ }^{166}$ SotinEL, 2005, págs. 96-97.

167 Verzár-BAss, 2000, passim.

${ }^{168}$ AndReolotti y otros, 1966, passim; Pross Gabrielli, 1975, passim; Cuscito, 1976, passim.

${ }^{169}$ S. II, 82-88.

${ }^{170}$ S. XVII, 39-46, 74-79. Un análisis más detallado de los Sermones II y XVII en Noce, 2011, págs. 159-169. 
acaso quepa definir el arribo de estos a la fe cristiana, en términos de Arthur Nock, más como actos de adhesión que de conversión ${ }^{171}$.

En consecuencia, al igual que los herejes ${ }^{172}$, los Iudaei proporcionaban a Cromacio de Aquileya un contramodelo de insuperable utilidad para instruir en las exigencias de la fe abrazada a los miembros de la propia comunidad religiosa. Reiterando los tópicos provistos por la literatura aduersus Iudaeos, el obispo exponía ante su auditorio un amplísimo repertorio de extravíos, no solo de naturaleza dogmática, como en el caso de los haeretici, sino también prácticos, morales y sociales, de los cuales esperaba apartar a sus fieles suscitando en ellos el temor a merecer, en vida, la vilipendiada imagen que del judío y del judaísmo se transmitía y, tras la muerte, el castigo eterno que inexorablemente aguardaba a los miembros del pueblo de Israel. De tal manera, la actualización de los elementos constituyentes de la denigración judaica no tenía otro objetivo que el de insistir respecto de la vigencia de los tópicos denunciados y de sus consecuencias: del mismo modo en que estos habían condenado a los judíos de antaño, conducían a la condena eterna a los del tiempo presente y, por extensión, a todos aquellos que, aún formando parte de la comunidad cristiana aquileyense, no ajustasen su comportamiento a las exigencias de la ortodoxia local al incurrir en uno o varios de los comportamientos y creencias atribuidos a los Iudaei por la tradición patrística y refrendados por el obispo de Aquileya.

\section{FUENTES}

Act. conc. Aquil. = Acta concili Aquileiensis: ed. por M. ZELZER, en CSEL, 82, 3 (1982).

Ambr. = Ambrosio de Milán

Epistulae: ed. por O. FALLER, en CSEL, 82, 1 (1968): Epistularum libri (I-IV); O. Faller \& M. Zelzer, en CSEL, 82, 2 (1990): Epistula-

${ }^{171}$ Nock defínía a la conversión como «the reorientation of the soul of an individual, his deliberate turning from indifference or from an earlier form of piety to another, a turning which implies a consciousness that a great change is involved, that the old was wrong and the new is right», en tanto que la adhesión constituía una «acceptance of new worships as useful supplements and not as substitutes» (Nock, 1988, pág. 7).

${ }^{172}$ Noce, en prensa (c). 
rum libri (VII-IX); M. ZELZER, en CSEL 82, 3 (1982): Epistularum liber $(\mathrm{X})$.

Chrom. $=$ Cromacio de Aquileya

Sermones: ed. por R. ÉTAIX \& J. LEMARIÉ, en CCSL IX A (1974) y J. LEMARIÉ \& R. ÉTAIX, en CCSL IX A Supplementum (1977).

Tractatus in Mathaeum: ed. por R. ÉTAIX \& J. LEMARIÉ, en CCSL IX A (1974), y J. Lemarié \& R. ÉtAIX, en CCSL IX A Supplementum (1977). Para el Tractatus L A se ha seguido el texto de R. ÉTAIX, «Un Tractatus in Matheum inédit de Saint Chromace d'Aquilée», Revue Bénédictine 91 (1981), 225-230.

Schol. conc. Aq. = Scholia in concilium Aquileiense $<$ Palladi Ratiarensis Fragmenta>: ed. por R. GRYSON, en CCSL 87, 1982.

\section{BIBLIOGRAFÍA}

Andreolotti, S.; Duda, S.; Faraone, E.; Gombassi, G.; Osenda, A.; Stradi, F. (1966), «Relazione sul rinvenimento dei resti di un Mitreo durante la disostruzione della cavità n. 4204 presso le risorgive del Timavo», en Atti e Memorie della Commissione Grotte "E. Boegan"», V, 1927.

Athans, M. Ch. (1991), «Antisemitism? or Anti-Judaism?», en A. SHE mis; E. A. Zannoni (eds.), Jewish-Christian Relations (New York: Paulist Press), 118-144.

Avneri, Z. (1962), «Lucerne giudaiche trovate in Aquileia», La Rassegna Mensile di Israel, XXVIII, 10, 466-469.

Banterle, G. (ed.) (1988), Opera omnia di Sant'Ambrogio. Lettere / 3 (Milano - Roma: Biblioteca Ambrosiana, Città Nuova).

Beatrice, P, F. (2011), «The Sign of Jonah. The Paschal Mystery and the Conversion of the Pagans according to Chromatius of Aquileia», en P. F. Beatrice; A. Peršič, Chromatius of Aquileia and His Age. Proceedings of the International Conference held in Aquileia, 2224 May 2008 (Turnhout: Brepols), 19-64.

Bertacchi, L. (1965), «La basilica di Monastero di Aquileia», Aquileia Nostra XXXVI, cc. 79-134. 
- (1980), «Architettura e mosaico», en AA.VV., Da Aquileia a Venezia. Una mediazione tra l'Europa e l'Oriente dal secolo II a.C. al VI secolo d.C. (Milano: Libri Scheiwiller), 99-336.

BRATOŽ, R. (1999), Il cristianesimo aquileiese prima di Costantino fra Aquileia e Poetovio (Gorizia - Udine: Istituto Pio Paschini, Istituto di Storia Sociale e Religiosa).

Brusin, G. (1947), «L'epigrafe musiva di “Petrus"», en Atti della Accademia Nazionale dei Lincei, s. VIII, v. 1, 18-20.

- (1949), «Un grande edificio cultuale a Monastero d'Aquileia», Bollettino d'Arte IV, XXXIV (1949), 351-357.

- (1949a), «Grande edificio cultuale scoperto a Monastero di Aquileia», Aquileia Nostra XX, cc. 25-30.

- (1953-54), «Orientali in Aquileia romana», Aquileia Nostra XXIV$\mathrm{XXV}$, cc. 55-70.

- \& P. L. Zovatto, Monumenti paleocristiani di Aquileia e di Grado (Udine: Deputazione di Storia Patria per il Friuli).

- $\quad$ (1991-93) $\dagger$ (ed.), Inscriptiones Aquileiae (Udine: Deputazione di Storia Patria per il Friuli), 3 vols.

CAlderini, A. (1930), Aquileia Romana. Richerche di storia e di epigrafia (Milano: Vita e Pensiero).

Cantino Wataghin, G. (2006), «Le basiliche di Monastero e di Beligna: forme e funzioni», en G. Cuscito (ed.), Antichità Altoadriatiche, LXII: Aquileia dalle origini alla costituzione del ducato longobardo. L'arte ad Aquileia dal sec. IV al IX (Trieste: Editreg), 303-333.

- (2008), «Le basiliche fuori le mura», en S. PIUssi (ed.), Cromazio di Aquileia 388-408. Al crocevia di genti e religioni (Milano: Silvana Editoriale), 346-353.

Cracco Ruggini, L. (1959), «Ebrei e orientali nell'Italia Settentrionale fra il IV e il VI secolo d. Cr.», en Studia et Documenta Historiae et Iuris 25, 186-308.

- (1977), «Il vescovo Cromazio e gli ebrei di Aquileia», en AA.VV., Antichità Altoadriatiche, XII: Aquileia e l'Oriente mediterraneo (Udine: Arti Grafiche Friulane), 353-381. 
- (1980), «Pietro di Grado: giudaismo e conversioni nel mondo antico», en AA.VV., Antichità Altoadriatiche, XVII, 1: Grado nella storia e nell'arte (Udine: Arti Grafiche Friulane), 139-160.

- (1979), Il paganesimo romano tra religione e politica (384-394 d. C.): per una interpretazione del Carmen contra paganos (Roma: Accademia Nazionale dei Lincei).

- (2008), "Cromazio di fronte a pagani ed ebrei”, en Piussi, S. (ed.), Cromazio di Aquileia 388-408. Al crocevia di genti e religioni (Milano: Silvana Editoriale), 184-191.

Cuscito, G. (1972), «Aspetti sociali della communità cristiana di Aquileia attraverso le epigrafi votive (secoli IV-VI)», en A. TAGLIAFERRI (ed.), Scritti storici in memoria di Paolo Lino Zovatto (Milano: Giuffrè), 237-258.

- (1976), «Revisione delle epigrafi di età romana rinvenute intorno al Timavo», en AA.VV., Antichità Altoadriatiche, X: Studi Monfalconesi e Duinati (Udine: Arti Grafiche Friulane), 47-62.

- (1979), «Introduzione», en G. Cuscito (ed.), Cromazio di Aquileia. Catechesi al popolo (Roma: Città Nuova), 7-35.

- (1980), Cromazio di Aquileia (388-408) e l'età sua. Bilancio bibliografico-critico dopo l'edizione dei Sermones e dei Tractatus in Mathaeum ([s. 1.]: Associazione Nazionale per Aquileia).

- (1987), Fede e politica ad Aquileia. Dibattito teologico e centri di potere (secoli $I V-V I$ ) (Udine: Del Bianco).

- (2002), «La prassi epigrafica dei cristiani in Alto Adriatico tra simbiosi e metabolismo», en M. Maritano (ed.), Historiam perscrutari. Miscellanea di studi offerti al prof. Ottorino Pasquato (Roma: LAS), 255-257.

- (2009), Signaculum Fidei. L'ambiente cristiano delle origini nell'Alto Adriatico: aspetti e problemi (Trieste: Editreg).

Ferrua, A. (1994), «Le iscrizioni antiche di Aquileia di G. B. Brusin», Rivista di Archeologia Cristiana LXX, 161-180.

Forlati TAmaro, B. (1965), «L'edifizio cultuale di Monastero di Aquileia e la sua interpretazione», en Atti del IV congresso Internazionale di Archeologia Cristiana (Ravena, 23-30 settembre 1962) (Città del Vaticano: Pontificio Istituto di Archeologia Cristiana), 659-671. 
Frey, J-B. (1936), Corpus Inscriptionum Iudaicarum. Recueil des inscriptions juives qui vont du III siècle avant Jésus-Christ au vII siècle de notre ère. Vol. 1. Europe (Città del Vaticano: Pontificio Istituto di Archeologia Cristiana).

Giovannini, A. (2008), «Lucerne ebraiche», en S. Piussi (ed.), Cromazio di Aquileia 388-408. Al crocevia di genti e religioni (Milano: Silvana Editoriale), 172-173.

GonzÁlez SAlinero, R. (2000), El antijudaísmo cristiano occidental (siglos $I V$ y $V$ ) (Madrid: Trotta).

- (2004), «Judíos y arrianos: el mito de un acercamiento inexistente», Sefarad 64, 27-74.

Granados, J.; Nieva, J. (2002), «Introducción», en J. Granados; J. Nieva (eds.), Cromacio de Aquileya. Comentario al Evangelio de Mateo (Madrid: Ciudad Nueva), 9-43.

Grassi, G. F. (2009), «Le dediche di Orientali nella basilica di Monastero di Aquileia», Aquileia Nostra LXXX, cc. 417-436.

Lemarié, J. (1969), «Introduction», en J. LemArIÉ, H. TARDIF (eds.), Chromace d'Aquilée. Sermons (Paris: Du Cerf), 9-120.

Lizzi, R. (1989), Vescovi e strutture ecclesiastiche nella città tardoantica (l'Italia Annonaria nel IV-V secolo d.C.) (Como: New Press).

Luzzato, F. (1950), «Ebrei in Aquileia», La Rassegna Mensile di Israel, XVI / 6-8 , 140-146.

Mazzoleni, D. (1987), «Un ebreo di Aquileia in un'iscrizione romana», en AA.VV., Antichità Altoadriatiche, XXX: Aquileia e Roma (Udine: Arti Grafiche Friulane), 309-315.

NAuroy, G. (2001), «Ambroise et la question juive à Milan à la fin du IVe siècle. Une nouvelle lecture de l'Epistula $74(=40)$ à Théodose», en J.-M. Poinsotte, (ed.), Les chrétiens face à leurs adversaires dans l'occident latin au IV siècle (Rouen: Université de Rouen), 37-59.

Noce, E. (2011), De catholici, gentiles, haeretici, Iudaei: la construcción de la identidad cristiana en el corpus de Cromacio de Aquileia (tesis doctoral, Universidad de Buenos Aires).

- (en prensa [a]), «Cromacio de Aquileia y el judaísmo. Reconsideración del Estado de la cuestión a la luz de los testimonios literarios y materiales", en AA.VV., Nuevas aproximaciones a la Antigüedad 
Grecolatina. Actas I Jornadas Interdisciplinarias de Jóvenes Investigadores de la Antigüedad Grecolatina (Buenos Aires, 16-17 de junio de 2011) (Buenos Aires: RHESIS).

- (en prensa [b]), «Sollemnitatem huius uigiliae nostrae tamquam propriam celebrant: reconsiderando el testimonio de Cromacio de Aquileya respecto de la Vigilia Pascual, los judíos y los gentiles (Sermo XVI, 61-69)», Anales de Historia Antigua, Medieval y Moderna 46.

- (en prensa [c]), «Herejía e identidad cristiana en el corpus de Cromacio de Aquileia», Anales de Historia Antigua, Medieval y Moderna 44.

Nock, A. D. (1988 [1933]), Conversion. The Old and the New in Religion from Alexander the Great to Augustine of Hippo (Boston: University Press of America).

Noy, D. (ed.) (1993), Jewish Inscriptions of Western Europe. Volume 1. Italy (excluding the City of Rome), Spain and Gaul (Cambridge: Cambridge University Press).

Noy, D. (ed.) (1995), Jewish Inscriptions of Western Europe. Volume 2. The City of Rome (Cambridge: Cambridge University Press).

Pietri, Ch. (1982), «Una aristocratie provinciale et la mision chrétienne: l'exemple de la Venetia», en AA.VV.,Antichità Altoadriatiche, XXII.1: Aquileia nel IV secolo (Udine: Arti Grafiche Friulane), 89-137.

Polacco, R. (1973), «L'antica sinagoga ebraica di Aquileia», en Atti dell'Accademia di Scienze, Lettere ed Arti di Udine, s. VIII, vol. $1,123-147$.

Pross Gabrielli, G. (1975), «Il tempietto ipogeo del dio Mitra al Timavo», Archeografo Triestino, s. IV, XXXV, 5-34.

Rapisarda, G. (2006), Cromazio di Aquileia, operatore di pace (Catania: C.U.E.C.M.).

RUEther, R. (1974), Faith and Fratricide. The Theological Roots of AntiSemitism (New York: Seabury Press).

- (1979), «The Adversus Iudaeos Tradition in the Church Fathers: the Exegesis of Christian Anti-Judaism», en P. E. Szarmach (ed.), Aspects of Jewish Culture in the Middle Ages: Papers of the Eighth 
Annual Conference of the Center for Medieval and Early Renaissance Studies (Albany: State University of New York Press), 2750.

Scholz, A. (1970 [1934]), «Il "Seminarium Aquileiense"», Memorie Storiche Forogiuliesi L, 7-106.

Simon, M. (1964 [1947]), Verus Israel. Étude sur les relations entre chrétiens et juifs dans l'Empire romain (135-425) (Paris: De Boccard).

Sotinel, C. (2005), Identité civique et christianisme. Aquilée du III au vie siècle (Rome: École Française de Rome).

- (2011), «L'évêque chrétien devant la diversité religieuse de la cité: Chromace et Aquilée», en P. F. BeAtrice; A. Peršič (eds.), Chromatius of Aquileia and His Age. Proceedings of the International Conference held in Aquileia, 22-24 May 2008 (Turnhout: Brepols), 163-176.

Stroumsa, G. S. (1996), «From Anti-Judaism to Antisemitism in Early Christianity?», en O. Limor, G. S. Stroumsa (eds.), Contra Iudaeos. Ancient and Medieval Polemics Between Christians and Jews (Tübingen: J. C. B. Mohr), 1-26.

TAYLOR, M. S. (1995), Anti-judaism and Early Christian Identity. A Critique of the Scholarly Consensus (Leiden-New York-Köln: Brill).

Thelamon, F. (2001), «Les vaines illusions des juifs incrédules selon Chromace et Rufin d'Aquilée», en Poinsotte, J.-M. (ed.), Les chrétiens face à leurs adversaires dans l'occident latin au IVe siècle (Rouen: Université de Rouen), 97-114.

Trettel, G. (1984), «Introduzione», en G. Trettel (ed.), Cromazio di Aquileia. Commento al Vangelo di Matteo, vol. 1 (Roma: Città Nuova), 7-38.

Truzzi, C. (1985), Zeno, Gaudenzio e Cromazio. Testi e contenuti della predicazione cristiana per le chiese di Verona, Brescia e Aquileia (360-410) (Brescia: Paideia).

Vattioni, F. (1972), «I nomi giudaichi delle epigrafi di Monastero di Aquileia», Aquileia Nostra, XLIII, cc. 125-132.

Vergone, G. (ed.) (2007), Le epigrafi lapidarie del Museo Paleocristiano di Monastero (Aquileia) (Trieste: Editreg). 
VerzÁR-BASS, M. (2000), «Continuità e trasformazione dei culti pagani ad Aquileia (II-IV secolo D.C.)», en G. BANDELli (ed.), Antichità Altoadriatiche, XLVII: Aquileia romana e cristiana fra II e v secolo (Trieste: Editreg), 147-178.

Zovatto, P. L. (1960-61), «Le antiche sinagoghe di Aquileia e di Ostia», Memorie Storiche Forogiuliese 44, 53-63.

Recibido: 08/03/2012

Aceptado: 30/05/2012 